
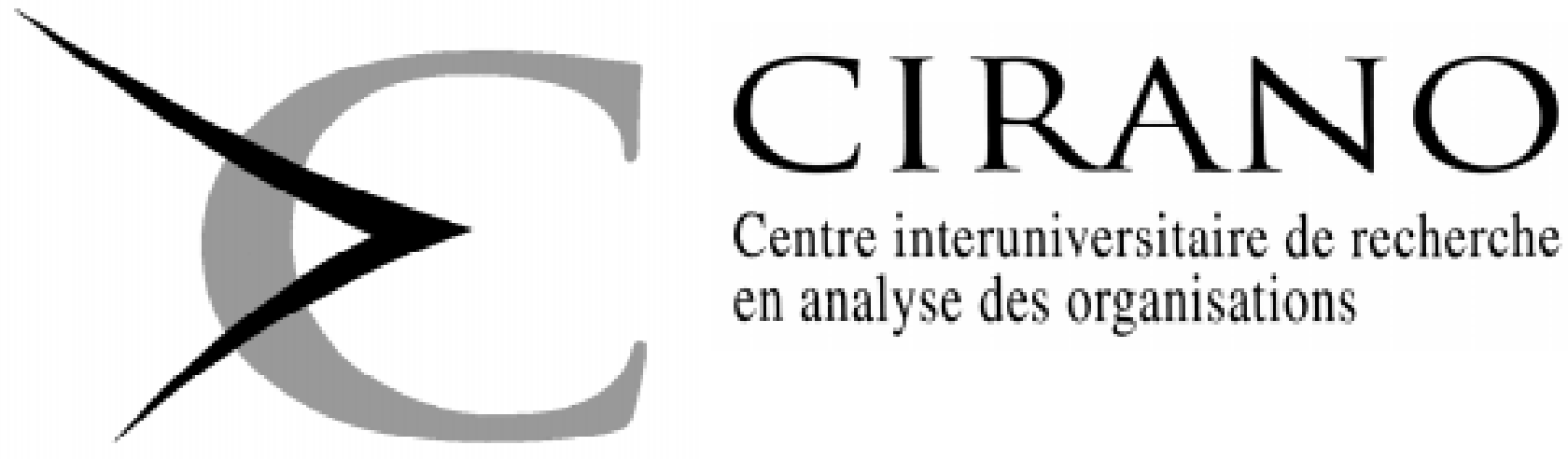

Centre interuniversitaire de recherche en analyse des organisations

Série Scientifique

Scientific Series

99s-13

Cost Manipulation Games in Oligopoly, with

Costs of Manipulating

Ngo Van Long, Antoine Soubeyran 


\section{CIRANO}

Le CIRANO est un organisme sans but lucratif constitué en vertu de la Loi des compagnies du Québec. Le financement de son infrastructure et de ses activités de recherche provient des cotisations de ses organisations-membres, d'une subvention d'infrastructure du ministère de l'Industrie, du Commerce, de la Science et de la Technologie, de même que des subventions et mandats obtenus par ses équipes de recherche. La Série Scientifique est la réalisation d'une des missions que s'est données le CIRANO, soit de développer l'analyse scientifique des organisations et des comportements stratégiques.

CIRANO is a private non-profit organization incorporated under the Québec Companies Act. Its infrastructure and research activities are funded through fees paid by member organizations, an infrastructure grant from the Ministère de l'Industrie, du Commerce, de la Science et de la Technologie, and grants and research mandates obtained by its research teams. The Scientific Series fulfils one of the missions of CIRANO: to develop the scientific analysis of organizations and strategic behaviour.

\section{Les organisations-partenaires / The Partner Organizations}

-École des Hautes Études Commerciales

-École Polytechnique

- Université Concordia

- Université de Montréal

-Université du Québec à Montréal

-Université Laval

- Université McGill

-MEQ

- MICST

-Alcan Aluminium Ltée

- Banque Nationale du Canada

- Bell Canada

-Développement des ressources humaines Canada (DRHC)

- Egis

- Fédération des caisses populaires Desjardins de Montréal et de l'Ouest-du-Québec

-Hydro-Québec

- Imasco

- Industrie Canada

- Microcell Labs inc.

- Raymond Chabot Grant Thornton

- Téléglobe Canada

-Ville de Montréal

() 1999 Ngo Van Long et Antoine Soubeyran. Tous droits réservés. All rights reserved.

Reproduction partielle permise avec citation du document source, incluant la notice (C).

Short sections may be quoted without explicit permission, provided that full credit, including () notice, is given to the source.

Ce document est publié dans l'intention de rendre accessibles les résultats préliminaires de la recherche effectuée au CIRANO, afin de susciter des échanges et des suggestions. Les idées et les opinions émises sont sous l'unique responsabilité des auteurs, et ne représentent pas nécessairement les positions du CIRANO ou de ses partenaires.

This paper presents preliminary research carried out at CIRANO and aims to encourage discussion and comment. The observations and viewpoints expressed are the sole responsibility of the authors. They do not necessarily represent positions of CIRANO or its partners. 


\title{
Cost Manipulation Games in Oligopoly, with Costs of Manipulating"
}

\author{
Ngo Van Long ${ }^{\dagger}$, Antoine Soubeyran ${ }^{\ddagger}$
}

\section{Résumé / Abstract}

\begin{abstract}
Ce papier étudie une classe de jeu de Cournot à deux étapes, où dans une première étape, des firmes rivales manipulent leurs coûts marginaux de production en supportant des coûts de manipulation, de manière à pouvoir choisir le type de jeu qu'elles veulent jouer en deuxième étape. Les coûts marginaux sont manipulés en redistribuant les actifs productifs, ou en choisissant leur localisation, ou en créant des marchés internes d'inputs. Une formulation générale de ce type de jeu, dit « jeux de manipulation des coûts avec coût à manipuler », est fournie, et plusieurs applications du modèle sont analysées. Nous montrons que souvent l'allocation optimale des ressources au sein d'un oligopole à la Cournot peut être asymétrique, même dans le cas ou les firmes sont symétriques ex-ante. Nous caractérisons le degré d'asymétrie en fournissant la solution globale d'un programme convexe (ou concave). Notre approche est assez générale pour pouvoir être appliquée aux jeux de Bertrand avec produits différenciés, aux jeux de localisation avec coût de transport (les modèles de Hotelling et de Salop) et aux jeux de Stackelberg.

This paper analyzes a class of two-stage Cournot games where rival firms, in the first stage, incur real resource costs in jointly manipulating their marginal costs of production, so as to influence the outcome of game they want to play in the second stage. Marginal costs may be manipulated by various means, such as redistribution of productive assets, or choice of location, or by creating an internal market for inputs. A general formulation of the game is provided, and several applications of the model are analyzed. We show that often the optimal allocation of resources within a Cournot oligopoly can be asymmetric, even when firms are ex ante symmetric, and we characterize the degree of asymmetry by finding a global solution to a convex (or concave) program. Our formulation of cost manipulation games with cost of manipulating is general enough to apply to Bertrand games with differentiated products, games involving location and transport costs (the Hotelling and Salop models), and Stackelberg games.
\end{abstract}

Mots Clés : Oligopole, jeux de Cournot, manipulation des coûts

Keywords : $\quad$ Oligopoly, Cournot games, cost manipulation

JEL : L13, L23

* Corresponding Author: Ngo Van Long, CIRANO, 2020 University Street, 25th floor, Montréal, Qc, Canada H3A 2A5 Tel: (514) 985-4011 Fax: (514) 985-4039 e-mail: longn@ @irano.umontreal.ca We are grateful to two referees for very helpful comments and suggestions. We thank Jacques Drèze, Gérard Gaudet, and Jean-François Thisse for comments.

${ }^{\dagger}$ McGill University and CIRANO

* GREQAM, Université de la Méditerranée 


\section{Introduction}

Firms in an oligopoly are not always in an adversarial relationship. In a recent book entitled "Co-opetition," Nalebuff and Brandenburger (1996) describe many real world situations of alliances between rival firms. They develop the theme that firms may modify the rules of their games in order to achieve partial cooperation while remaining rivals in the final good market $^{1}$. Their insightful discussion is an invitation for economists to develop a unifying framework for the analysis of a class of games in which rival firms have the ability, in an earlier stage of the game, to determine the set of actions or outcomes that are admissible in the subsequent subgames. An interesting example of two-stage games that involve cooperation at one level and rivalry at another level is the creation of competing divisions within a multi-divisional firm. Baye, Crocker and Ju (1996) analyze "strategic incentives to divide production among autonomous competing units through divisionalization, franchising, or divestiture". A related phenomenon is the establishment of an internal input market within an oligopoly, of which the intrafirm resource flows and knowlegde flows constitute a special case. It may be argued that these flows are created partly to influence the outcome of rivalry in a second stage of a game. Trade between parent firms and their foreign affiliates that are potential rivals (e.g. Sony products made in Malaysia versus almost identical Sony products made in China) may be analyzed in terms of a two-stage game. The importance of intrafirm resource flows is well documented in the World Investment Report (1993). In manufacturing, the share of intrafirm transactions in foreign sales by US foreign affiliates rose from 30 per cent to 36 per cent over the period 1977-89. Data for the US on royalties and licence fees indicate that more than 70 per cent of all receipts and 50 per cent of all payments were intra-transnational corporation transactions (World Investment Report, 1993, p.164.).

Another example of two-stage games is the formation of a production joint venture (denoted as PJV, as distinct from research joint venture, RJV) by rival firms ${ }^{2}$. Many production joint ventures have the features that participants that use the joint venture's output as their intermediate inputs are rivals in the final good market. Gale (1994) cites as examples (i) firms sharing natural gas pipelines, (ii) an aluminium rolling mill jointly owned by Alcan and Arco. Participants cooperate in the alloca-

\footnotetext{
${ }^{1}$ The semi-collusion aspect of oligopoly has been emphasized by Friedman and Thisse (1993), and Fershtman and Gandal (1994).

${ }^{2}$ See Spencer and Raubitschek (1996), Gale (1994) for models of PJVs, and d'Aspremont and Jacquemin (1988), Suzumura (1992), Kamien et al. (1992) for RJVs.
} 
tion of the output of the PJV to them, who act as rivals in a diferent stage of the game. ${ }^{3}$

In this paper we provide a general methodology for analyzing a class of two-stage games among oligopolists, and illustrate the usefulness of our approach by considering a number of applications. We are concerned with "games of cost manipulation in the presence of costs of manipulation". The costs of manipulating costs play an important role. These costs may be in the form of internal production of an essential input, capacity choice, or choice of the firm's locatio, etc. We seek to characterize the solution of this type of games in terms of the concavity or convexity of the overall objective function in the first stage. Our resolution is geometric in nature. We show that the stage one objective function may display, under quite general assumptions, a fundamental convexity in the choice variables.

A major common thread in the applications that we focus on is the following broad issue: why do internal markets for certain crucial inputs emerge within an oligopoly? It will be seen that a large organization consisting of independent rival units may have an incentive to generate an internal input market as a means of fostering collusion. While we analyse only a few examples, it will become clear that our framework is suitable for the analysis of various aspects of behavior of multi-divisional firms, multi-national firms, production joint ventures, and so on. In addition to providing a general framework of analysis, we also obtain some specific results. Among these is the result that, contrary to the general presumption that ex-ante symmetric firms will choose to be ex-post symmetric in their joint profit maximization decisions, it is quite often the case that the solution of the above class of games is asymmetric, even if firms are ex-ante symmetric. The intuition behind this result is as follows. In a Cournot oligopoly ${ }^{4}$, with a fixed number of firms each having a constant marginal cost, the equilibrium industry output in stage 2 depends only on the sum of their marginal costs (see Bergstrom and Varian (1985a)); it follows that if this sum is kept constant, while some firms' marginal costs are made to increase and other firms'marginal costs are made to decrease, then industry output, price, and total revenue will remain un-

\footnotetext{
${ }^{3}$ Two-stage games of a similar nature, with or without collusion or government intervention in the first stage, include learning-by-doing by oligopolists (first period output levels have an influence on second period cost; see Fudenberg and Tirole (1983), Krouse (1994) for example); technology choice (investment decision concerning equipment types in period one determines the level of constant marginal cost in period two; see DeGraba (1990), and Newbery (1990, especially pp.344-345).

${ }^{4}$ More generally, a modified version of his result applies also to Bertrand games, Stackelberg games, and games involving location such as the Hotelling and Salop models.
} 
changed, and therefore industry profit will rise because the same total output is now produced at lower cost (as firms with decreased marginal costs will expand their market shares at the expense of firms with increased marginal costs). This is the efficiency motive for cost manipulation. In the context of a simple model of research joint venture without the cost of manipulating costs, this result has been formalized by Long and Soubeyran $^{5}$ (1995a): industry profit is an increasing function of the variance of the distribution of the constant marginal costs. In this paper, we deal with the issue of manipulation of marginal costs in a much more general fashion, by (i) introducing real resource costs of manipulating costs, (ii) providing a global characterization of the solution, and (iii) dealing with both the cases of constant marginal costs and rising marginal costs. Our approach relies on the decomposition principle (see Rockafellar, 1970, Section 28, or Luenberger 1969, Ch. 8).

It is clear from the above discussion that asymmetric solution to a symmetric problem arises when there is lack of concavity in the objective function. By deriving the properties of the equilibrium profit function for oligopoly, our model explains a key source of this lack of concavity. But we should point out that there are situations where the cost of manipulation of costs has a high degree of convexity, so that the objective function becomes concave, giving rise to the optimality of symmetric solutions. Both cases are discussed in Section 2, where we also treat the more realistic case where firms are ex-ante asymmetric.

The paper is organized as follows. In Section 2 we present the general methodology and some general results, under the assumption that marginal costs are independent of the scale of output. Section 3 extends the results to the case of multiplicatively separable scale-dependent marginal costs. In Section 4 we illustrate the use of our general method on some specific applications. Section 5 and the Appendix offers some

\footnotetext{
${ }^{5}$ A closely related result was proved by Bergstrom and Varian (1985b). They assume that firms have identical constant marginal costs, but face different tax rates, and show that tax revenue is a decreasing function of the variance of the tax rates. At a less formal level, several authors have provided numerical examples where an increase in the dispersion of (constant) marginal costs in a duopoly will increase the sum of their profits. See Newbery (1990, pp. 344-345) and Salant and Shaffer (1992). Neither paper gave a formula relating industry profit to the variance of the distribution of marginal costs and both papers assumed linear demand. While working on the present paper, we received a paper by Salant and Shaffer (1996) addressing the same topic. The latter paper gives sufficient conditions for a solution to be asymmetric, in terms of gains achieved by a marginal deviation from a symmetric point. Our approach is different: we provide a global resolution of a convex or concave problem, and characterize fully the degree of asymmetry. The question concerning the (integer) number of firms achieving different levels of cost reduction in the optimal solution is also answered.
} 
further extensions.

\section{The Model}

We consider an oligopoly consisting of $m$ firms that produce a homogenous good. Let $M \equiv\{1,2, \ldots, m\}$. Let $q_{i}$ denote firm $i$ 's output, $i \in M$. The inverse demand function is

$$
P=P(Q), \quad P^{\prime}(Q)<0
$$

where $Q=\sum_{i \in M} q_{i}$. (Generalization to the case where $P=P\left(Q+Q^{*}\right)$ where $Q^{*}$ is the output of another set of firms, possibly located somewhere else, can be easily achieved at a small cost, in terms of additional notation.) Assume that firm i's current marginal cost of production is independent of its current output level $q_{i}$ but is dependent on the level of a choice variable made in an earlier stage, such as the firm's investment in capital equipment, or the amount of entrepreneurial time committed to monitoring, or accumulated experience, or the result of $R \& D$ in previous periods. For simplicity, we represent this variable by a non-negative real number $e_{i}$. We capture the cost-saving effect of $e_{i}$ by postulating that the marginal cost of output is decreasing in $e_{i}$.

$$
c_{i}\left(e_{i}\right)=\bar{c}_{i}-r_{i}\left(e_{i}\right), \quad r_{i}(0)=0, \quad r_{i}^{\prime}\left(e_{i}\right) \geq 0
$$

where $r_{i}($.$) is the reduction in marginal cost.$

In some applications, the cost reduction achieved by one firm may depend not only on its choice variable (such as its nominal R\&D expenditure) but also on the activity of other firms (eg. their nominal R\&D expenditures) because of spillover effects. In such cases, our formulation (1) need to be re-interpreted; for example, in the presence of R\&D spillovers, $e_{i}$ would then represents firm $i$ 's effective $\mathrm{R} \& \mathrm{D}$, which is a variable that takes into account the spillover effects.(See Long and Soubeyran (1995b).)

The class of two-stage Cournot games considered in this paper has the following main charateristic: in the first stage, the variables $e_{i}$ are either collusively determined, or are independently chosen by the firms under the direct influence of a dominant actor (as in the case of a government agency that allocates firm-specific R\&D subsidies, or that imposes firm-specific pollution standards). This determines each firm's constant marginal cost in stage two, when the firms are Cournot rivals. In the case of collusive behavior in stage one, the objective is to maximize

joint profits. In the case of a dominant actor, the objective may be to 
maximize some social welfare function if the dominant actor is a government agency. Regardless of the specific formulation of the problem in stage one, a necessary step in understanding the game is to analyze the Cournot equilibrium in stage two. We now turn to this task.

\subsection{Analysis of Cournot equilibrium in stage two}

At the beginning of stage two, the variables $e_{i}$ have been chosen. Firm $i$ 's marginal cost is then $c_{i}\left(e_{i}\right)$, which we denote in this subsection by $c_{i}$ for short. We assume that for each $i$ the feasible range of $e_{i}$ is $\left[0, e_{i}^{\max }\right]$. This means $c_{i}$ is restricted in the range $\left[c_{i}^{\min }, \bar{c}_{i}\right]$, where $c_{i}^{\min } \equiv \bar{c}_{i}-r_{i}\left(e_{i}^{\max }\right)$. Firms compete in quantities. At a Cournot equilibrium, outputs are determined by the following conditions:

$$
\begin{gathered}
\frac{\partial \pi_{i}}{\partial q_{i}}=P^{\prime}(\widehat{Q}) \widehat{q}_{i}+P(\widehat{Q})-c_{i} \leq 0 \\
\widehat{q}_{i} \geq 0, \quad \widehat{q}_{i} \frac{\partial \pi_{i}}{\partial q_{i}}=0
\end{gathered}
$$

In addition, if $\widehat{q}_{i}>0$, then the following second order condition must hold: $P^{\prime \prime}(\widehat{Q}) \widehat{q}_{i}+2 P^{\prime}(\widehat{Q}) \leq 0$. This condition may be expressed as

$$
2-s_{i} E \geq 0
$$

where $E \equiv-P^{\prime \prime}(\widehat{Q}) \widehat{Q} / P^{\prime}(\widehat{Q})$ is the elasticity of the slope of the demand curve and $s_{i} \equiv \widehat{q}_{i} / \widehat{Q}$ is firm $i$ 's market share.

Assumption S: The second order condition (4) is satisfied.

We will consider only situations where the values of $\left(c_{1}, \ldots, c_{m}\right)$ are such that all firms produce in equilibrium, and where for each vector $\left(c_{1}, \ldots, c_{m}\right)$ there exists a unique Cournot equilibrium. (Sufficient conditions for the existence and uniqueness of Cournot equilibria are given by Nishimura and Friedman (1981), Kolstad and Mathieson (1989), Gaudet and Salant (1991), Long and Soubeyran (1999.) Under the assumption that (2) holds with equality for all firms, the sum of these $m$ equations yields

$$
P^{\prime}(\widehat{Q}) \widehat{Q}+m P(\widehat{Q})=\sum_{i \in M} c_{i} \equiv C
$$

where $C$ is the sum of the marginal costs. Note that $C$ is restricted in the range $\left[C^{\min }, C^{\max }\right]$ where $C^{\min } \equiv \sum_{i \in M} c_{i}^{\min }$ and $C^{\max } \equiv \sum_{i \in M} \bar{c}_{i}$. As pointed out by Bergstrom and Varian (1985a), equation (5) shows that equilibrium industry output depends only on the sum of the marginal 
costs. To ensure uniqueness and interiority of the solution, additional assumptions are imposed below.

Given $m$, we define the function

$$
\psi(Q)=P^{\prime}(Q) Q+m P(Q), \quad \psi(0)=m P(0)>0
$$

Clearly, if $\psi(Q)$ is a decreasing function for all $Q>0$ and if there exists some $Q^{\#}>0$ such that $\psi(Q)<0$ for all $Q$ greater than $Q^{\#}$, then (5) has a unique solution $\widehat{Q}=\widehat{Q}(C)$ for each $C$ in the interval $0 \leq C \leq m P(0)$. The condition that $\psi(Q)$ is decreasing can be expressed as $P^{\prime \prime}(Q) Q+(m+1) P^{\prime}(Q)<0$, or equivalently as

$$
E<m+1
$$

where $E$ is the elasticity of the slope of the demand curve. Condition (6) is also a familiar stability condition for Cournot equilibria (see Dixit (1986), for example). Finally, the assumption that the equilibrium output $q_{i}$ is positive for all firms is justified if $P(Q(C))>c_{i}$. (If the demand function is $P=A-B Q$, a sufficient condition for this is $A>(m+1) c_{i}$.) It is useful to state our assumptions more formally:

Assumption E: There exists some positive $Q^{\#}$ such that $\psi\left(Q^{\#}\right)$, $\psi(Q)<0$ for all $Q$ greater than $Q^{\#}$, and for all output level $Q<Q^{\#}$, the elasticity of the slope of the demand curve is less than $m+1$.

Assumption I: For all $C$ in the range $\left[C^{\min }, C^{\max }\right], c_{i}<P(\widehat{Q}(C))$ for all $i$.

Assumption I ensures that all firms produces in equilibrium. We are now ready to state a few important lemmas, the first one being a simple re-statement of a result stated in Bergstrom-Varian (1985a). ${ }^{6}$

Lemma 1:Under assumptions S, E and I, the equilibrium industry output $\widehat{Q}$ is uniquely determined by $C$ and is independent of the distribution of marginal costs among the oligopolists.

Having determined the function $\widehat{Q}(C)$, we can now express the equilibrium output of firm $i$, and its equilibrium profit, as a function of only two parameters, $C$ and $c_{i}$.

Lemma 2:Under Assumptions S, E and I, firm $i$ 's equilibrium output is

$$
\widehat{q}_{i}=\frac{P(\widehat{Q}(C))-c_{i}}{\left[-P^{\prime}(\widehat{Q}(C))\right]} \equiv \widehat{q}_{i}\left(c_{i}, C\right)
$$

\footnotetext{
${ }^{6}$ Bergstrom and Varian $(1985 \mathrm{a}, \mathrm{b})$ noted that several authors had been aware of this result.
} 
and its equilibrium profit is given by

$$
\pi_{i}=\left[P(\widehat{Q}(C))-c_{i}\right] \widehat{q}_{i}=\frac{\left[P(\widehat{Q}(C))-c_{i}\right]^{2}}{\left[-P^{\prime}(\widehat{Q}(C))\right]} \equiv \pi_{i}\left(c_{i}, C\right)
$$

We now turn to industry profit in a Cournot equilibrium. Using Lemma 2, it is easy to arrive at the following result:

Proposition 1( The Industry Equilibrium Profit Function): Average industry profit in a Cournot equilibrium, under Assumptions $\mathrm{S}, \mathrm{E}$ and $\mathrm{I}$, is a linear and increasing function of the variance of the distribution of marginal costs accross firms:

$$
\pi_{M}=\sum_{i \in M} \frac{\pi_{i}\left(c_{i}, C\right)}{m}=\frac{V_{M}(\mathbf{c}, C)+[P(\widehat{Q}(C))-(C / m)]^{2}}{\left[-P^{\prime}(\widehat{Q}(C))\right]} \equiv \pi_{M}(\mathbf{c}, C)
$$

where $\mathbf{c} \equiv\left(c_{1}, \ldots, c_{m}\right)$ is the vector of marginal costs and $V_{M}(\mathbf{c}, C)$ is the variance of their distribution:

$$
V_{M}(\mathbf{c}, C) \equiv \frac{1}{m} \sum_{i \in M}\left[c_{i}-(C / m)\right]^{2} \equiv \frac{1}{m} \sum_{i \in M}\left[c_{i}-c_{M}\right]^{2}
$$

Proof: Summing (8) over all firms to obtain

$$
\begin{gathered}
{\left[-P^{\prime}\right] m \pi_{M}=\sum_{i \in M}\left[\left(\widehat{P}-c_{M}\right)+\left(c_{M}-c_{i}\right)\right]^{2}} \\
=\sum_{i \in M}\left(c_{M}-c_{i}\right)^{2}+\sum_{i \in M}\left(\widehat{P}-c_{M}\right)^{2}
\end{gathered}
$$

Remark: The second term in the numerator of (9) is the square of the average mark-up.

The intuition behind Proposition 1 is as follow. Take the simplest case where the industry consists of two identical firms. Now let firm 1's constant marginal cost be shifted upward by $\epsilon$ and that of firm 2 be shifted downward by $\epsilon$. The two reaction functions will then be shifted, one outwards and the other inwards, in a compensating fashion, and hence the industry equilibrium output will remain unchanged. Hence the equilibrium price and industry revenue are unaffected. On the other hand, industry production cost will be lower than before, because more than half of industry output will be produced by the lower cost firm. It follows that industry profit will be greater than before. 
The above argument shows that the Cournot oligopolists have an incentive to affect a change in the distribution of marginal costs among firms as the gainers can more than compensate the losers, if such redistribution does not use up any significant amount of real resources and does not violate anti-trust laws. In what follows, we deal with the more general case where the manipulation of marginal costs involves real resource costs.

The next result links average industry profit to the Herfindahl index of industry concentration:

Corollary 1:(Link between Industry Profit and the Herfindahl Index) Given the marginal cost sum $C$, the equilibrium industry profit is an increasing function of the Herfindahl index of concentration.

Proof: See the Appendix.

Next, consider social welfare, defined as the sum of consumers' surplus and producers' surplus. Consumers' surplus is

$$
S(\widehat{Q}) \equiv \int_{0}^{\widehat{Q}} P(\tilde{Q}) d \tilde{Q}-\widehat{Q} P(\widehat{Q})
$$

Since $\widehat{Q}=\widehat{Q}(C)$ in a Cournot equilibrium, social welfare is

$$
W(\mathbf{c}, C) \equiv S(\widehat{Q}(C))+m \pi_{M}(\mathbf{c}, C)
$$

From (12) and Corollary 1, we obtain the following result:

Corollary 2: For a given sum $C$ of marginal costs, an increase in the Herfindahl index, made possible by increasing the dispersion of the distribution of marginal costs, will improve both industry profit and social welfare.

\subsection{Analysis of Stage 1: Manipulation of Marginal Costs}

We now turn to Stage 1. This stage is characterized by some sort of collusive behavior. In the most obvious applications, the rival firms collude by reallocating resources among themselves so that for any given marginal cost sum $C$ they maximize their joint profits. The problem would be trivial if firms can costlessly "redistribute" their marginal costs, 
in the sense that one firm's marginal cost could be reduced by $\epsilon$ as long as another firm's marginal cost is increased by $\epsilon$. We deal with the more realistic case where redistribution of marginal costs involves real costs, which may be called "cost of manipulating costs".

It is convenient to invert the cost reduction function $r_{i}\left(e_{i}\right)$ to obtain $e_{i}=e_{i}\left(r_{i}\right)$, where $r_{i}$ is restricted to be in the interval $\left[0, r_{i}^{\max }\right]$. With a slight abuse of notation, we express the dependence of equilibrium output on $C$ in an alternative form:

$$
\widehat{Q}=\widehat{Q}\left(r_{M}\right)
$$

where

$$
r_{M} \equiv \frac{1}{m} \sum_{i \in M} r_{i}
$$

The direct cost to firm $i$ for taking action $e_{i}$ will be denoted by $\phi_{i}\left(e_{i}\right)$. Then firm $i$ 's net profit is

$$
\pi_{i}^{n e t} \equiv \frac{\left[P\left(\widehat{Q}\left(r_{M}\right)\right)-\bar{c}_{i}+r_{i}\right]^{2}}{\left[-P^{\prime}\left(\widehat{Q}\left(r_{M}\right)\right)\right]}-\phi_{i}\left(e_{i}\left(r_{i}\right)\right)
$$

The objective function for the problem in stage one is to maximize net joint profits

$$
m \pi_{M}^{n e t} \equiv \frac{1}{\left[-P^{\prime}\left(\widehat{Q}\left(r_{M}\right)\right)\right]} \sum_{i \in M}\left[P\left(\widehat{Q}\left(r_{M}\right)\right)-\bar{c}_{i}+r_{i}\right]^{2}-\sum_{i \in M} \phi_{i}\left(e_{i}\left(r_{i}\right)\right)
$$

subject to $0 \leq r_{i} \leq r_{i}^{\max }$.

To facilitate an intuitive comprehension of the nature of this problem, and particularly, to sharpen the focus on the crucial issue of asymmetric versus symmetric solutions, it is helpful to decompose the problem (16) into two subproblems. First, for a given $r_{M}$, how should the $r_{i}$ 's be chosen? The second subproblem is the choice of the optimal $r_{M}$. It is the first subproblem that commands our attention here, because the question of optimality of asymmetric allocation when firms are ex-ante symmetric is not well understood. The separation of the two subproblems has the flavor of the traditional separation of income and substitution effects in the theory of the consumer, or the separation of cost minimization from profit maximization in the theory of the firm.

To summarize, in the first subproblem, we take a given $r_{M}$ and seek to maximize $\pi_{M}$ by choosing a non-negative vector of cost reductions $\mathbf{r}$ 
belonging to a feasible set $G\left(r_{M}\right)$ defined by

$$
G\left(r_{M}\right) \equiv\left\{\left(r_{1}, \ldots, r_{m}\right): 0 \leq r_{i} \leq r_{i}^{\max }, \sum_{i=1}^{m} r_{i}=m r_{M}\right\}
$$

The solution of this subproblem ${ }^{7}$ yields $r_{i}=r_{i}\left(r_{M}\right)$. In the second subproblem, the optimum $r_{M}$ is determined. The main merit of this two-step procedure is that when we fix $r_{M}$ we effectively fix the Cournot equilibrium price and thus we are able to separate the revenue considerations, as represented by the term $P\left(Q\left(r_{M}\right)\right) Q$, from the cost minimization considerations (the allocation of cost reductions among firms, holding $r_{M}$ constant, and the tradeoff between, on the one hand, the efficiency gain resulting from this allocation, and on the other hand, the costs of manipulating costs, as represented by the change in the sum of the $\phi_{i}\left(e_{i}\right)$ 's). In what follows we will analyze the first subproblem only, and the the second subproblem will be dealt with in Appendix 2.

Let us define the vector $\mathbf{x} \equiv\left(x_{1}, \ldots, x_{m}\right)$ where

$$
x_{i} \equiv \bar{c}_{i}-P\left(\widehat{Q}\left(r_{M}\right)\right)
$$

(One may interpret $-x_{i}=P-\bar{c}_{i} \equiv m_{i}$ as the profit margin, net of $r_{i}$ ). Then given $r_{M}$ the objective function (16) becomes:

$$
\max _{r} \psi(\mathbf{r}) \equiv \frac{1}{\left[-P^{\prime}\left(\widehat{Q}\left(r_{M}\right)\right)\right]}\|\mathbf{r}-\mathbf{x}\|^{2}-\sum_{i=1}^{m} \phi_{i}\left(e_{i}\left(r_{i}\right)\right)
$$

where $\|\mathbf{r}-\mathbf{x}\|^{2} \equiv v(\mathbf{r})$ is the square of the Euclidean distance between the vector $\mathbf{r}$ (to be chosen from the set $G\left(r_{M}\right)$ ) and the fixed vector $\mathbf{x}$. Let

$$
\phi(\mathbf{r}) \equiv \sum_{i=1}^{m} \phi_{i}\left(e_{i}\left(r_{i}\right)\right)
$$

If $\phi()=$.0 identically then the problem (19) is simply one of finding a point $\mathbf{r}$ in the set $G\left(r_{M}\right)$ that is of maximal distance from the given point $\mathbf{x}$. Since $v(\mathbf{r})$ is a strictly convex function, and $G\left(r_{M}\right)$ is a convex set defined by linear inequalities, the solution must occur at a corner of the feasible set $G\left(r_{M}\right)$.

In general $\phi($.$) is not zero. We will focus on three cases. In the first$ two cases, we assume that all firms are ex-ante identical, so that for all $i$ in $\{1,2, \ldots, m\}, \bar{c}_{i}=\bar{c}, r_{i}^{\max }=r^{\max }$, etc., while in the third case, we

\footnotetext{
${ }^{7}$ It can be shown that all $q_{i}$ are positive when the $r_{i}$ 's are between 0 and $r^{\text {max }}$.
} 
allow firms to be ex-ante asymmetric, but the function $\phi($.$) is strictly$ concave.

Case 1 (Ex ante identical firms, strictly concave objective function): $\phi($.$) is sufficiently convex in \mathbf{r}$ such that $\psi(\mathbf{r})$ is strictly concave in $\mathbf{r}$ despite the convexity of $v(\mathbf{r})$.

Case 2 (Ex ante identical firms, strictly convex objective function): $\phi($.$) is concave or linear (or only mildly convex) in \mathbf{r}$, so that $\psi(\mathbf{r})$ is strictly convex in $\mathbf{r}$.

Case 3 (Ex ante asymmetric firms, strictly concave objective function)

Clearly, in Case 1 , for any given $r_{M} \in\left[0, r^{\max }\right]$ the solution is

$$
r_{1}=r_{2}=\ldots=r_{m}=r_{M}
$$

This follows from the fact that $\psi($.$) is symmetric and strictly concave$ in $\left(r_{1}, \ldots, r_{m}\right)$.

In Case 2, we consider two subcases.

Subcase (2a): $m r_{M}<r^{\max }$

Subcase (2b): $m r_{M} \geq r^{\max }$

Without loss of generality, we adopt the convention that whenever there is an asymmetric solution -that is, $r_{i} \neq r_{j}$, for some pair $(i, j)$ - we will describe it in the form $r_{1} \geq r_{2} \geq r_{3} \geq \ldots \geq r_{m}$. We now state our results For both cases:

Proposition 4: Assume that firms are ex-ante identical.

(i) If the objective function $\psi(\mathbf{r})$ is strictly convex (i.e., case 2 ), then

- Under Subcase (2a), the solution is

$$
r_{1}=m r_{M}<r^{\max } \quad, \quad r_{2}=r_{3}=\ldots=r_{m}=0
$$

- Under Subcase $(2 \mathrm{~b})$, let $m^{0}$ denote the greatest positive integer that belongs to the set $K\left(r_{M}\right)$ of all positive integers $k$ that satisfies the inequality $k r^{\max } \leq m r_{M}$. The solution is: if $m^{0} r^{\max }=m r_{M}$, then

$$
r_{1}=r_{2}=\ldots=r_{m^{0}}=r^{\max }, \quad r_{j}=0, \quad j \geq m^{0}+1
$$

and if $m^{0} r^{\max }<m r_{M}$, then

$$
\begin{gathered}
r_{1}=r_{2}=\ldots=r_{m^{0}}=r^{\max }, \quad r_{m^{0}+1}=r^{+}<r^{\max }, \\
r_{j}=0, \quad j \geq m^{0}+2
\end{gathered}
$$

where $r^{+} \equiv m r_{M}-m^{0} r^{\max }>0$. 
(ii) If the objective function $\psi(\mathbf{r})$ is strictly concave, i.e., Case 1 , then the solution is symmetric, as given by (21).

(iii) If $\psi(\mathbf{r})$ is neither concave nor convex, then it is possible to have two or more levels of cost reductions that are in the interior of the set $G\left(r_{M}\right)$.

Remark: Proposition 4 tells us that, given that firms are ex-ante identical, in the strictly convex case, the solution is asymmetric in a simple way: there are at most three types of firms, with one bunch at the top (achieving the maximum possible cost reduction), one bunch at the bottom (achieving no reduction in cost) and at most a single firm that achieves an intermediate level of cost reduction, $r^{+}$.

We now outline the proof of part (i) of Proposition 4. Part (ii) is obvious, and for part (iii) the reader is referred to the example in Long and Soubeyran (1995b) in the context of research joint ventures.

Proof: From (19), and (17) we form the Lagrangian

$$
L=\psi(\mathbf{r})+\lambda\left[m r_{M}-\sum_{i \in M} r_{i}\right]+\sum_{i \in M} \mu_{i} r_{i}+\sum_{i \in M} \eta_{i}\left[r^{\max }-r_{i}\right]
$$

where $\psi(\mathbf{r})$ may be expanded as follows

$$
\psi(\mathbf{r}) \equiv \frac{1}{\left[-\widehat{P^{\prime}}\right]} \sum_{i \in M}\left[r_{i}-r_{M}\right]^{2}+\frac{m\left[\widehat{P}-\bar{c}+r_{M}\right]^{2}}{\left[-\widehat{P^{\prime}}\right]}-\sum_{i \in M} \phi_{i}\left(e_{i}\left(r_{i}\right)\right)
$$

First, we must prove that it is not possible to have a solution with more than one firm achieving intermediate level of cost reductions. We offer a proof by contradiction. Thus, suppose at the solution point there are two firms, say $i$ and $j$, with $0<r_{i}<r^{\max }$, and $0<r_{j}<r^{\max }$. Then for $h=i, j$

$$
\frac{2\left(r_{h}-r_{M}\right)}{\left[-\widehat{P^{\prime}}\right]}-\frac{\partial \phi_{h}}{\partial r_{h}}=\lambda, \quad h=i, j
$$

Since the left-hand side of (24) is increasing in $r_{h}$ (due to the assumption that $\psi($.$) is convex), it follows that r_{i}=r_{j}=r^{*}$, say. But then a small departure from this common value $r^{*}$ by adding $\epsilon$ to $r_{i}$ and substracting $\epsilon$ from $r_{j}$ will improves the value of $\psi(\mathbf{r})$ as given in (23). In particular, note that the first term on the right hand side of (23) is the familiar variance expression, which will increase with such a departure. At the same time, the "cost of manipulating costs term", the third term, being the sum of $m$ identical concave functions, decreases with such a departure. It follows that at most one firm can have an intermediate cost reduction level $0<r<r^{\max }$. 
More formally, let $\chi(x)$ denote the greatest integer smaller than or equal to the real number $x$. The requirements that (i) $\sum_{i \in M} r_{i}=m r_{M}$, (ii) at most one $r_{i}$ is in the interior of $\left[0, r^{\max }\right]$, and (iii) $0 \leq r_{j} \leq r^{\max }$ imply that there is only one solution:

$$
\begin{gathered}
m^{0}=\chi\left[\frac{m r_{M}}{r^{\max }}\right], \quad r_{j}=r^{\max } \text { for all } j \leq m^{0} \\
r_{m^{0}+1}=m r_{M}-m^{0} r^{\max }, \quad r_{h}=0 \text { for all } h \geq m^{0}+2
\end{gathered}
$$

This concludes the proof. $\square$

So far we have focussed on the two polar cases with ex ante identical firms, where $\psi$ is either (strictly) concave, or (strictly) convex. If $\psi$ is neither concave nor convex, then it is possible to have two or more levels of cost reduction that are strictly interior even though firms are initially identical. See Long and Soubeyran (1995b) for this case.

We now turn to case 3, where firms are ex-ante asymmetric. For simplicity we assume that the function $\psi(\mathbf{r})$ is strictly concave. Proposition 5 below characterizes the optimal cost reductions. For givem $r_{M}$, let us define

$$
\psi_{i}\left(r_{i}\right)=\frac{1}{\left(-P^{\prime}\right)}\left[P-\bar{c}_{i}+r_{i}\right]^{2}-\phi_{i}\left(e_{i}\left(r_{i}\right)\right)
$$

$\psi_{i}$ is assumed to be strictly concave. Let $y_{i}=\psi_{i}^{\prime}\left(r_{i}\right)$ and $\bar{y}_{i}=\psi_{i}^{\prime}\left(r_{i}^{\max }\right)$. Without loss of generality, let $\bar{y}_{1} \leq \bar{y}_{2} \leq \ldots \leq \bar{y}_{m}$. Assume that at the optimum all firms strictly reduces their unit cost. Then there will be two subsets of firms, denoted by $M^{+}$and $\bar{M}$ such that all firms $j$ in $\bar{M}$ reduce their cost by the maximum posssible amount, $r_{j}^{\max }$, while all firms $i$ in $M^{+}$reduce their cost by less than $r_{i}^{\max }$. Clearly, the optimal cost reductions for all the firms in $M^{+}$must satisfy $\psi_{i}^{\prime}\left(r_{i}^{*}\right)=\lambda$ (a constant). Applying the inverse function of $\psi_{i}^{\prime}$, we have $r_{i}^{*}=\psi_{i}^{\prime-1}(\lambda) \equiv \omega_{i}(\lambda)$. We define $\Omega(\lambda)=\sum_{i \in M^{+}} \omega_{i}(\lambda)$.

Proposition 5: (The ex-ante asymmetric case, with strictly concave $\left.\psi_{i}\left(r_{i}\right)\right)$

If at the optimum all firms reduce their costs then there exists an integer $m^{+} \leq m$ such that all firms in the set $M^{+}$of indices $i=1,2, \ldots, m^{+}$ achieve the cost reduction $r_{i}^{*}=\omega_{i}(\lambda)$ and all firms in the set $\bar{M}=$ $\left\{m^{+}+1, \ldots, m\right\}$ achieve their respective maximum cost reduction $r_{j}^{\max }$. The optimal $\lambda$ and $m^{+}$satisfy the following conditions

$$
\Omega(\lambda)=m r_{M}-\sum_{j \in \bar{M}} r_{j}^{\max } \quad, \quad \bar{y}_{m^{+}} \leq \lambda<\bar{y}_{m^{+}+1}
$$

Proof: Omitted. 


\section{Generalization: Increasing Marginal Costs}

We now provide an extension of the results presented in the previous section to the case of increasing marginal costs. Instead of assuming that marginal cost is independent of output, we now suppose that firm $i$ has a mutiplicatively separable cost function ${ }^{8}$

$$
C_{i}\left(q_{i}, \alpha_{i}\right) \equiv \alpha_{i} c\left(q_{i}\right)
$$

where $c(0)=0, c^{\prime}\left(q_{i}\right)>0, c^{\prime \prime}\left(q_{i}\right) \geq 0$ and $\alpha_{i}>0$. The $\alpha_{i}$ 's are in turn functions of the amount of resource $k_{i}$ used by firm $i$ to reduce its cost: $\alpha_{i}=\alpha_{i}\left(k_{i}\right)$, with $\alpha_{i}(0)=\bar{\alpha}_{i}>0, \alpha_{i}^{\prime}\left(k_{i}\right)<0$ for $0 \leq k_{i} \leq \bar{k}$ and $\alpha_{i}(\bar{k})=\underline{\alpha}_{i}>0$. No restriction is placed on $\alpha_{i}^{\prime \prime}\left(k_{i}\right)$. The direct cost to firm $i$ of procuring the amount of resource $k_{i}$ is $\phi_{i}\left(k_{i}\right)$.

In the second stage of the game, the $k_{i}$ 's have been chosen. The Cournot equilibrium in the second stage implies the following conditions

$$
\widehat{q_{i}} \widehat{P^{\prime}}+\widehat{P}=\alpha_{i} c^{\prime}\left(\widehat{q}_{i}\right) \equiv \theta_{i}
$$

where the hat over $P$ and $q_{i}$ indicate that they are values at the Cournot equilibrium, and $\theta_{i}$ is the (non-constant) marginal cost (also at the Cournot equilibrium) of firm $i$. The second order condition is

$$
\widehat{q_{i}} \widehat{P^{\prime \prime}}+2_{i} \widehat{P^{\prime}}-\alpha_{i} c^{\prime \prime}\left(\widehat{q_{i}}\right) \leq 0
$$

Summing (27) over all $i$

$$
\widehat{Q} \widehat{P^{\prime}}+m \widehat{P}=\sum_{i \in M} \theta_{i} \equiv m \theta_{M}
$$

which gives $\widehat{Q}=\widehat{Q}\left(\theta_{M}\right)$.

From (27),

$$
\widehat{q}_{i}=\frac{\widehat{P}-\theta_{i}}{\left[-\widehat{P}^{\prime}\right]}
$$

therefore, at the Cournot equilibrium,

$$
\alpha_{i}=\frac{\theta_{i}}{c^{\prime}\left(\widehat{q}_{i}\right)}=\frac{\theta_{i}}{c^{\prime}\left[\frac{\widehat{P}-\theta_{i}}{\left(-\widehat{P}^{\prime}\right)}\right]} \equiv g_{i}\left(\theta_{i}, \theta_{M}\right)
$$

\footnotetext{
${ }^{8}$ The results of this subsection remain basically unchanged in more general convex cost formulation. The assumption of multiplicative separability in this subsection helps simplify the exposition. See Appendix A2 for the general case.
} 
The equilibrium profit function for firm $i$ in stage two is

$$
\pi_{i}\left(\theta_{i}, \theta_{M}\right) \equiv\left[\frac{\widehat{P}-\theta_{i}}{\left(-\widehat{P^{\prime}}\right)}\right] \widehat{P}\left(\widehat{Q}\left(\theta_{M}\right)\right)-\frac{\theta_{i} c\left[\frac{\widehat{P}-\theta_{i}}{\left(-\widehat{P}^{\prime}\right)}\right]}{c^{\prime}\left[\frac{\widehat{P}-\theta_{i}}{\left(-\widehat{P}^{\prime}\right)}\right]}
$$

Invert the function $\alpha_{i}\left(k_{i}\right)$ to obtain $k_{i}=k_{i}\left(\alpha_{i}\right)$ defined over $\left[\underline{\alpha}_{i}, \bar{\alpha}_{i}\right]$ with $k_{i}\left(\bar{\alpha}_{i}\right)=0$ and $k_{i}^{\prime}<0$. Firm $i$ 's net profit is

$$
\pi_{M}^{n e t} \equiv \pi_{i}\left(\theta_{i}, \theta_{M}\right)-\phi_{i}\left(k_{i}\left(\alpha_{i}\right)\right)
$$

where $\alpha_{i}$ is given by the third expression in equation (30).

The objective function in stage one is to maximize net joint profits by choosing the vector $\theta=\left(\theta_{1}, \ldots, \theta_{m}\right)$ :

$$
m \pi_{M}^{n e t} \equiv \sum_{i \in M} \pi_{i}\left(\theta_{i}, \theta_{M}\right)-\sum_{i \in M} \phi_{i}\left(k_{i}\left(g_{i}\left(\theta_{i}, \theta_{M}\right)\right)\right)
$$

This may be re-written as

$$
m \pi_{M}^{n e t} \equiv \sum_{i \in M}-f\left(\theta_{i}, \theta_{M}\right)-\sum_{i \in M} \phi_{i}\left(k_{i}\left(g_{i}\left(\theta_{i}, \theta_{M}\right)\right)\right)+\frac{m\left[\widehat{P}-\theta_{M}\right] \widehat{P}}{\left[-\widehat{P^{\prime}}\right]}
$$

where

$$
f\left(\theta_{i}, \theta_{M}\right) \equiv \frac{\theta_{i} c\left[\frac{\widehat{P}-\theta_{i}}{\left(-\widehat{P^{\prime}}\right)}\right]}{c^{\prime}\left[\frac{\widehat{P}-\theta_{i}}{\left(-\widehat{P}^{\prime}\right)}\right]}
$$

The method of analysis used in Section 2 can be applied to this more general formulation: First, for a given $\theta_{M}$, choose the $\theta_{i}$ 's to maximize the objective function subject to $\sum_{i \in M} \theta_{i}=m \theta_{M}$. The next step is to choose $\theta_{M}$. A special case of interest is where $c($.$) has a constant$ elasticity, $c^{\prime}(q) q / c(q) \equiv \epsilon=$ constant. (Note that $\epsilon=1$ in the case of constant marginal costs.)Then

$$
f\left(\theta_{i}, \theta_{M}\right)=\frac{\theta_{i} \widehat{P}\left[1-\theta_{i}\right]}{\left[-\widehat{P^{\prime}}\right] \epsilon}
$$

which is convex in $\theta_{i}$ 's for given $\theta_{M}$. This shows clearly that asymmetric solution can emerge even with increasing marginal costs. In fact using (35) the gross profit function can be expressed as

$$
\pi_{M}=\frac{\widehat{P}}{\left[-\widehat{P^{\prime}}\right]}\left[\widehat{P}-\theta_{M}\left(\frac{1+\epsilon}{\epsilon}\right)\right]+\frac{\theta_{M}^{2}+V_{M}}{\left[-\widehat{P^{\prime}}\right] \epsilon}
$$


where $V_{M}$ is the variance of the distribution of marginal costs, defined as $V_{M} \equiv(1 / m) \sum_{i \in M}\left[\theta_{i}-\theta_{M}\right]^{2}$. Note that $1 / \epsilon$ is a measure of the degree of increasing return. If it is not a constant, a similar furmula can be derived, using an 'adjusted' variance.

Finally, corollary 2 (the link between industry profit and the Herfindahl index) can be generalized to the non-constant cost case. Let $\epsilon_{i}\left(q_{i}\right) \equiv$ $q_{i} c^{\prime}\left(q_{i}\right) / c\left(q_{i}\right)$ and let $q_{M} \equiv(1 / m) \sum_{i \in M} q_{i}$ denote the mean output. Define the adjusted mean output by $q_{M}^{a} \equiv(1 / m) \sum_{i \in M}\left[q_{i} / \epsilon_{i}\right]$. Then we can show that industry profit in a Cournot equilibrium is related to an adjusted Herfindahl index:

$$
m \pi_{M}=m\left[q_{M}-q_{M}^{a}\right] \widehat{P}+\left(-\widehat{P^{\prime}}\right) \widehat{Q}^{2} H_{M}^{a}
$$

where $H_{M}^{a}$ is the adjusted Herfindahl index defined by

$$
H_{M}^{a} \equiv \sum_{i \in M} \frac{1}{\epsilon_{i}}\left[\frac{\widehat{q}_{i}}{\widehat{Q}}\right]^{2}
$$

\section{Applications}

In this section we illustrate the usefulness of our approach by applying it to a number of problems. The models we consider below exhibit a common theme: an internal allocation problem is solved within an oligopoly, and the solution often takes the form of the emergence of an internal market for productive resources. This solution has a collusive effect on the behavior of the firms (or independent divisions of a multi-divisional firm) that must behave as rivals in the second stage. The outcome may involve unequal treatment of equals. While we focus on multi-divisional firms and transfer of productive assets, other obvious applications suggest themselves: production joint-ventures, subcontracting, internal market for intermediate goods. External input markets can also be analyzed in a similar fashion. One can think of problems such as reciprocal access, and access pricing (in telecommunication, for example), the establishment of an input-purchasing cartel, and so on.

\subsection{Divisionalization and capacity decisions}

An interesting question in the industrial organization literature is: what are the motives for a firm to set up several competing divisions that produce almost identical products. (See Baye et al.(1996) for some real world examples.) Several reasons have been offered as possible explanation. Firstly, divisionalization can be a response to the loss of operational 
control when a firm become too large, see Williamson (1975). Secondly, a monopolist may use divisionalization as a commitment mechanism for producing an output level that would prevent entry (see Schwartz and Thompson (1986), and Veendorp (1991)). Thirdly, given the divisionalization decisions of its rivals, an existing oligopolist may have an incentive to divisionalize (see Baye et al. (1996)) in order to increase its profit; this result is the mirror image of the proposition that mergers that do not result in monopoly (or near monopoly) are generally not profitable, under the assumption that merging leaves unchanged the production cost (see Salant et al. (1983)). Here, we add another consideration: if the capacity decisions by the divisionalized firm is made by the center, and not by the divisions themselves, should the allocated capacities be the same for all divisions?

Veendorf (1991) has pointed out that while divisions are allowed to make their own output decisions, capacity decisions are often made centrally. He showed that centralized capacity decisions can improved the profit of a divisionalized firm. However, he assumed for simplicity that all divisions have the same allocated capacity, or capital stock. In this sub-section, we apply our method developed in Sections 2 and 3 to shed light on the possible optimality of asymmetric capacity allocation by a divisionalized firm.

We now describe our model. A monopolist is facing the threat of entry of a potential rival firm. He must decide whether to accommodate entry, or to pre-empt it. The game structure is as follows. In stage 1, the monopolist decides on the number of independent divisions it will set up. These divisions are instructed to maximize divisional profit, and to behave as Cournot rivals. In stage 2, the monopolist makes centralized capacity decision for each division. (Here, we interpret "capacity" not as an upper limit on output, but as the size of the capital stock, which affects marginal cost.) In stage 3 , the potential entrant chooses whether to enter or not, and the number of divisions to be set up if it enters; at this stage it incurs a set-up cost $A_{e}>0$ per division if the decision is to enter. In stage four, if there is entry, then the divisions of the entrant and the divisions of the incumbent compete as Cournot rivals; if there is no entry, the divisions of the incumbent also compete as Cournot rivals.

We solve the game backwards, and consider stage four first. Suppose that entry has taken place in stage 3 . Assume for simplicity that the entrant is a divisionalized firm with $n$ divisions, all with the same capacity, and that each of the entrant's division has a constant marginal cost $\theta_{e}$. The incumbent has $m$ divisions, and the capacity of division $i$ is $k_{i}$. Let $q_{i}$ denotes the output of division $i$. We assume that the variable cost of producing $q_{i}$ is $\alpha\left(k_{i}\right) c\left(q_{i}\right)$, where $c^{\prime}>0$, and $c^{\prime \prime} \geq 0$, and $a^{\prime}<0$. 
Division $i$ also has incurred (in stage 2) the cost $F_{i}=A+\phi\left(k_{i}\right)$. (The $k_{i}$ 's are determined in Stage 2.) Given entry, the Cournot equilibrium ${ }^{9}$ in stage four is characterized by (27) for each division $i(i=1, \ldots, m)$, and, for each division $j$ of the entrant,

$$
\widehat{q}_{e j} \widehat{P^{\prime}}+\widehat{P}=\theta_{e} \quad(j=1, \ldots, n .)
$$

(we assume that the Cournot equilibrium is an interior solution.) Summing (38) over $j$ and the $m$ equations (27), we obtain an expression similar to $(28)$ :

$$
\widehat{Q} P^{\prime}(\widehat{Q})+(m+n) P(\widehat{Q})=m \theta_{M}+n \theta_{e}
$$

This gives $\widehat{Q}=\widehat{Q}\left(m \theta_{M}+n \theta_{e}, m+n\right)$. From the definition of $\theta_{i}$,

$$
\widehat{q}_{i}=c^{\prime-1}\left(\theta_{i} / \alpha\left(k_{i}\right)\right)=c^{\prime-1}\left(\theta_{i} / \alpha_{i}\right)
$$

A conventional way to proceed would be to substitute this into (27) to get $\theta_{i}=\widehat{\theta}_{i}\left(\alpha_{i}, m \theta_{M}+n \theta_{e}, m+n\right)$. From this, and $m \theta_{M}=\sum_{\iota} \theta_{i}$, we would obtain (with a slight abuse of notation) $\theta_{i}=\widehat{\theta}_{i}\left(\boldsymbol{\alpha}, n \boldsymbol{\theta}_{e}, m+n\right)$, where $\boldsymbol{\alpha}=\left(\alpha_{1}, \ldots, \alpha_{m}\right)$ and where $\alpha_{i}$ stands for $\alpha\left(k_{i}\right)$. Using (29), the equilibrium net profit of the incumbent's division $i$ in stage four, given entry, is

$\widehat{\pi}_{i}^{n e t}=\left[\frac{\widehat{P}-\theta_{i}}{\left(-\widehat{P}^{\prime}\right)}\right] P\left(\widehat{Q}\left(m \theta_{M}+n \theta_{e}, m+n\right)\right)-\alpha\left(k_{i}\right) c\left[\frac{\widehat{P}-\theta_{i}}{\left(-\widehat{P}^{\prime}\right)}\right]-\phi\left(k_{i}\right)-A$

where $\theta_{i}$ stands for $\widehat{\theta}_{i}\left(\boldsymbol{\alpha}, n \boldsymbol{\theta}_{e}, m+n\right)$ and $m \theta_{M}$ stands for $\sum_{i} \widehat{\theta}_{i}\left(\boldsymbol{\alpha}, n \boldsymbol{\theta}_{e}, m+\right.$ $n$ ). In stage 2 , the incumbent divisionalized firm would choose the $k_{i}$ 's $(i=1, \ldots, m)$.

It is analytically more convenient, however, to use the approach developed in section 3 , and obtain

$$
\alpha_{i}=\frac{\theta_{i}}{c^{\prime}\left(\widehat{q}_{i}\right)}=\frac{\theta_{i}}{c^{\prime}\left[\frac{\widehat{P}-\theta_{i}}{\left(-\widehat{P}^{\prime}\right)}\right]} \equiv g\left(\theta_{i}, m \theta_{M}+n \theta_{e}, m+n\right)
$$

From this, we proceed to obtain expressions similar to (31)-(34) in section 3. For concreteness, let us take the cost function $c(q)=(1 / \varepsilon) q^{\varepsilon}$ where $\varepsilon \geq 1$, and the demand function $P=1-Q$. Then in a Cournot equilibrium, the equilibrium net profit of the incumbent's division $i$ is

\footnotetext{
${ }^{9}$ We assume that sufficient conditions for uniqueness, such as those given in Gaudet and Salant (1991), or Long and Soubeyran (1999), are met.
} 


$$
\widehat{\pi}_{i}^{n e t}=\widehat{P} \widehat{q}_{i}-\frac{1}{\varepsilon} \theta_{i} \widehat{q}_{i}-\phi\left(k_{i}\left(\alpha_{i}\right)\right)-A
$$

where $\alpha_{i}=g\left(\theta_{i}, m \theta_{M}+n \theta_{e}, m+n\right)$, as is given in (40). Using (27), and $P^{\prime}=-1$, we re-write (41) as:

$$
\widehat{\pi}_{i}^{n e t}=\left[\widehat{P}-\frac{\theta_{i}}{\varepsilon}\right]\left(\widehat{P}-\theta_{i}\right)-\phi\left[k_{i}\left(g\left(\theta_{i}, m \theta_{M}+n \theta_{e}, m+n\right)\right)\right]-A
$$

where $\widehat{P}=P\left(\widehat{Q}\left(m \theta_{M}+n \theta_{e}, m+n\right)\right)$.

The gross profit (before substracting the set-up cost which has been incurred in Stage 3) of each division $j$ of the entrant is

$$
\widehat{\pi}_{e j}=\left(\widehat{P}-\theta_{e}\right)^{2}
$$

(using (38) with $P^{\prime}=-1$.)

In Stage 3, the potential entrant decides whether it should enter, and if it does enter, how many divisions it will have. No entry means that $n=0$. It follows from (42) that, in Stage 3, the potential entrant will not enter if

$$
\left[P\left(\widehat{Q}\left(m \theta_{M}+n \theta_{e}, m+n\right)\right)-\theta_{e}\right]^{2}<A_{e}
$$

for all $n \geq 1$. (It can be shown that if (43) holds for $n=1$ then it also holds for $n>1$ : an increase in the number of rivalrous divisions will reduce the net profit of each division, and hence, if each division is making a negative net profit, the sum of their net profits will fall. $\left.{ }^{10}\right)$. The potential entrant's decision can be written as $n^{*}=n^{*}(\boldsymbol{\alpha}, m)$.

In Stage 2, given that the number of divisions of the incumbent firm is $m$, the incumbent decides on the investment allocations across its divisions. This amounts to choosing the $\alpha_{i}$ 's, taking as given the potential entrant's decision rule $n^{*}=n^{*}(\boldsymbol{\alpha}, m)$, to maximize

$$
m \pi_{M}^{n e t}=\sum_{i=1}^{m} \widehat{\pi}_{i}
$$

subject to $\underline{\alpha} \leq \alpha_{i} \leq \bar{\alpha}$.

In what follows, due to space limitation, we will restrict attention to the case where parameter values are such that the incumbent finds it optimal to prevent entry. Then $\theta_{M}$ is chosen to satisfy (43). We

\footnotetext{
${ }^{10}$ If each division is making a positive net profit, an increase in the number of divisions may increase the sum of their net profits, even though each division's net profit will fall.
} 
then seek to find out if, at the optimal $\theta_{M}$, the investment allocation is asymmetric. An example will suffice. Assume the function form

$$
k(\alpha)=\bar{\alpha}-\alpha, \quad \underline{\alpha} \leq \alpha \leq \bar{\alpha}
$$

and $\phi(k)=\gamma k, \gamma>0$. Then from (40) $\alpha_{i}=\theta_{i} /\left(\widehat{P}-\theta_{i}\right)^{\varepsilon-1}$. Thus

$$
\begin{aligned}
m \pi_{M}^{n e t} & =\left[\widehat{P} \sum_{i=1}^{m}\left(\widehat{P}-\theta_{i}\right)\right]-\left[\frac{1}{\varepsilon} \sum_{i=1}^{m} \theta_{i}\left(\widehat{P}-\theta_{i}\right)\right] \\
& -m A-\gamma m \bar{\alpha}+\sum_{i=1}^{m} \gamma \theta_{i} /\left(\widehat{P}-\theta_{i}\right)^{\varepsilon-1}
\end{aligned}
$$

where $\widehat{P}=P\left(Q\left(m \theta_{M}\right)\right)$. If $\varepsilon=1$, then $\alpha_{i}=\theta_{i}$ and problem (44) reduces to maximizing with respect to the $\theta_{i}$

$$
m \pi_{M}^{n e t}=m\left(\widehat{P}-2 \theta_{M}\right) \widehat{P}-m A-\gamma m \bar{\alpha}+\gamma m \theta_{M}+\sum_{i=1}^{m} \theta_{i}^{2}
$$

subject to $\sum_{i=1}^{m} \theta_{i}=m \theta_{M}$ (given) and $\underline{\alpha} \leq \theta_{i} \leq \bar{\alpha}$. Clearly, since $m \pi_{M}^{n e t}$ is convex and increasing in the $\theta_{i}$ 's, the solution of this constrained maximization problem is a corner one. For example, if $m=2$ and $\theta_{M}$ is such that $2 \underline{\alpha}<2 \theta_{M}<\underline{\alpha}+\bar{\alpha}$, then, given $\theta_{M}$, the optimal pair $\left(\theta_{1}, \theta_{2}\right)$ is $\left(\underline{\alpha}, \theta_{M}-\underline{\alpha}\right)$, which is asymmetric.

Similarly, if $\varepsilon=2$, then $\alpha_{i}=\theta_{i} /\left(\widehat{P}-\theta_{i}\right)$. Then the constraint $\underline{\alpha} \leq$ $\alpha_{i} \leq \bar{\alpha}$ is equivalent to

$$
\frac{\bar{\alpha} \widehat{P}}{\bar{\alpha}+1} \geq \theta_{i} \geq \frac{\underline{\alpha} \widehat{P}}{\underline{\alpha}+1}
$$

and again a corner solution is possible if $\gamma$ is small.

Symmetric solutions emerge if the function $\phi(k)$ is sufficiently convex. For example, if $\phi(k)=\gamma k^{2}$ and $\gamma$ is sufficiently great, then the optimal solution is symmetric.

A digression: The optimal number of divisions.

As noted above, if $\phi(k)$ is sufficiently convex, we will have a symmetric solution. In this case, under linear demand, it is relatively simple to calculate the optimal number of divisions from the point of view of the incumbent firm. 


\subsection{Production Joint Ventures}

It is not uncommon for rival firms to jointly own a production joint venture. For examples, rival gas distributors may own a common gas pipeline, which reduce their distribution costs. In stage 1 , the firms jointly decide on the total capacity of the pipeline, and the fraction of the total capacity to be allocated to individual participants. In stage 2, they are Cournot rivals. We will show that, under certain conditions, firms that are ex-ante symmetric would find it profitable to be unequal ex-post.

Let $E$ denote the capacity of the pipeline, and $U(E)$ the total cost of having that capacity. Let $e_{i}$ denote the amount of capacity allocated to firm $i$, and $E=\sum_{i=1}^{m} e_{i}$. Here we assume that capacity does not constrain output, but it has a favorable impact on distribution cost: the greater is the capacity, the lower is the distribution cost per unit. Consider first the final stage of the game, when the decisions on the $e_{i}$ 's (and hence on $E$ ) have been made. Firm $i$ 's distribution cost per unit of output is given by (1). Assume that firm $i$ must pay a share of the capacity cost. Its payment is $\rho(E) e_{i}$ where $\rho(E)=U(E) / E$. Firm $i$ 's net profit is

$$
\pi_{i}^{n e t}=P q_{i}-\left[\bar{c}_{i}-r_{i}\left(e_{i}\right)\right] q_{i}-\rho(E) e_{i}
$$

Again, we invert $r_{i}\left(e_{i}\right)$ to get $e_{i}=e_{i}\left(r_{i}\right)$.

The equilibrium net profit is

$$
\pi_{i}^{n e t} \equiv \frac{\left[P\left(\widehat{Q}\left(r_{M}\right)\right)-\bar{c}_{i}+r_{i}\right]^{2}}{\left[-P^{\prime}\left(\widehat{Q}\left(r_{M}\right)\right)\right]}-\rho\left(\sum_{j=1}^{m} e_{j}\left(r_{j}\right)\right) e_{i}\left(r_{i}\right)
$$

The sum of the profits is

$$
m \pi_{M}^{n e t} \equiv \frac{1}{\left[-P^{\prime}\left(\widehat{Q}\left(r_{M}\right)\right)\right]}\|\mathbf{r}-\mathbf{x}\|^{2}-\rho\left(\sum_{j=1}^{m} e_{j}\left(r_{j}\right)\right)\left[\sum_{i j+1}^{m} e_{j}\left(r_{j}\right)\right]
$$

where $\mathbf{x}$ is a vector with the typical component $x_{i}$ given by (18). In the first stage of the games, the firms jointly make the decisions on the $r_{i}$ 's to maximize the sum of their profits, given that they will be rivals in the product market. It is easy to construct numerical examples showing that the optimal solution involves asymmetric allocation of capacity to participants of the production joint ventures. (An example is available from the authors, upon request.) 


\subsection{Interfirm Transfer of Productive Assets}

This section is an attempt to incorporate the idea, advanced by managerial writers, that firms are characterized by collections of resources that must be developed internally. This is known the resource-based approach $^{11}$. The resource-based view tends to explain differences in performance across firms in terms of access to, and ability to develop valuable resources that enhance efficiency. We sketch below a model in which firms develop their resources internally with a view of reducing cost. We then add the observation that rival firms may transfer internally developed resources among themselves as a means of fostering collusion $^{12}$.

Consider a Cournot oligopoly consisting of $n$ firms. The first $m$ firms are called the insiders, for example, they are independent divisions of a multi-divisional firms, or affiliates of a transnational corporation. The remaining $m^{*}(=n-m)$ firms are the outsiders. Let $M \equiv\{1,2, \ldots, m\}$ and $M^{*} \equiv\left\{m+1, \ldots, m+m^{*}\right\}$. Firm $i$ 's marginal cost is $c_{i}=\bar{c}_{i}-r_{i}\left(k_{i}\right)$ where $k_{i}$ is the amount of resources used to reduced production cost. These resources may be internally trained managers, or scientists. We assume that $r_{i}(0)=0, r_{i}^{\prime}\left(k_{i}\right) \geq 0$, and $r_{i}\left(k_{i}\right) \leq r_{i}^{\max } \leq \bar{c}_{i}$ for all $k_{i}$. In the absence of interfirm transfer of resources, each firm would have to produce its own $k_{i}$, at the cost $\phi\left(k_{i}\right)$. Define $C \equiv \sum_{i \in M} c_{i} \equiv m c_{M}$, $C^{*} \equiv \sum_{j \in M^{*}} c_{j} \equiv m^{*} c_{M^{*}}, Q \equiv \sum_{i \in M} q_{i}$ and $Q^{*} \equiv \sum_{j \in M^{*}} q_{j}$. Let $P=P(Z)$, where $Z \equiv Q+Q^{*}$. A straightforward generalization of Lemma 1 shows that the equilibrium output is a function of $C+C^{*}$.

Using an argument similar to the proof of Proposition 1, we obtain

$$
\pi_{M}^{n e t}=\widetilde{\pi}_{M}-\frac{1}{m} \sum_{i \in M} \phi_{i}\left(k_{i}\right)
$$

where

$$
\begin{aligned}
\tilde{\pi}_{M} & =\frac{V_{M}+\left[\widehat{P}-c_{M}\right]^{2}}{\left[-\widehat{P^{\prime}}\right]} \\
\pi_{M^{*}}^{n e t} & =-\frac{1}{m^{*}} \sum_{i \in M^{*}} \phi_{i}\left(k_{i}\right)
\end{aligned}
$$

where

$$
\tilde{\pi}_{M^{*}}=\frac{V_{M^{*}}+\left[\widehat{P}-c_{M^{*}}\right]^{2}}{\left[-\widehat{P^{\prime}}\right]}
$$

\footnotetext{
${ }^{11}$ See Foss, Knudsen and Montgomery (1995, pp. 6-8.) for a survey, and the references listed therein.

${ }^{12}$ Our model can also be interpreted as a more general version of the model of transfer of capital by Farrell and Shapiro (1990a).
} 
The Herfindahl index for group $M$ is

$$
H_{M} \equiv \sum_{i \in M}\left[\frac{q_{i}}{Z}\right]^{2}=\frac{m \pi_{M}}{\left[-P^{\prime}\right] Z^{2}}
$$

From (47) and (45)

$$
\frac{H_{M}}{m}=\frac{V_{M}+\left[\widehat{P}-c_{M}\right]^{2}}{\left[-\widehat{P^{\prime}}\right]^{2} Z^{2}}=\frac{V_{M}+\left[\widehat{P}-c_{M}\right]^{2}}{n^{2}\left[\widehat{P}-c_{N}\right]^{2}}
$$

where $c_{N}=\left(C+C^{*}\right) / n$. This shows that, for a given sum of marginal costs, the combined profit of group $M$ is an increasing function of its Herfindahl index, which is in turn an increasing function of the variance of marginal costs within the group. It follows that if marginal costs could be costlessly redistributed within the group without changing the marginal cost sum $C$, then firms in group $M$ would have an incentive to maximize their Herfindahl index.

However, since in general the relationship between a firm's stock of resources $k_{i}$ and its marginal cost is not linear, a transfer of resources will change the marginal cost sum. This will change the equilibrium industry output and price, at the same time as it changes the variance of marginal costs. Therefore one cannot conclude that a resource transfer from a small firm to a large firm is always profitable for the group $M$. A convenient way of analyzing this problem is to use the analogue of the function $\psi($.$) of Section 2$.

For given $r_{M^{*}} \equiv\left(1 / m^{*}\right) \sum_{j \in M^{*}} r_{j}$, the firms in group $M$ reallocate the internally produced resources among themselves to maximize the sum of their profits. Let $v_{i}$ denote firm $i$ 's production of the resources, $i \in M$ and let $v_{i}-k_{i}$ denote the net transfer it makes to other firms in the group. Let $k_{i}\left(r_{i}\right)$ be the inverse of the function $r_{i}\left(k_{i}\right)$. Given any $r_{M} \geq 0$, consider the set

$$
G\left(r_{M}\right) \equiv\left\{\left(r_{1}, \ldots, r_{m}\right): 0 \leq r_{i} \leq r_{i}^{\max }, \sum_{i \in M} r_{i}=m r_{M}\right\}
$$

For any given $r_{M}$, group $M$ chooses a vector $r=\left(r_{1}, \ldots, r_{m}\right)$ in $G\left(r_{M}\right)$ to maximize the sum of their net profits

$$
m \pi_{M}^{n e t}=\frac{1}{\left[-\widehat{P^{\prime}}\right]} \sum_{i \in M}\left[\widehat{P}-\bar{c}_{i}+r_{i}\right]^{2}-\frac{1}{m} \sum_{i \in M} \phi_{i}\left(v_{i}\right)
$$

subject to $\sum_{i \in M} v_{i} \equiv \sum_{i \in M} k_{i}\left(r_{i}\right)$. The analysis in Section 2 applies to this problem without any significant modification. 


\section{Further Extensions and Other Applica- tions}

Our framework can also be modified to deal with semi-collusion in models of Bertrand competition in prices, Hotelling model of location choice, Salop model of firms located on a circle, and Stackelberg games ${ }^{13}$. It can be seen from the analysis in the preceding sections (and from the Appendix) that our formulation applies generally to games where each player has a pay-off function $G_{i}\left(\beta_{i}, a_{i}, \sum a_{j}\right)$ where $a_{i}$ is agent $i$ 's action, and $\beta_{i}$ is a parameter of manipulation cost. The first stage of the game involves solving a sub-convolution problem of the form

$$
\max _{\theta_{i}} \sum_{i \in M} f_{i}\left(\theta_{i}, \theta_{M}\right)
$$

subject to $\sum_{i \in M} g_{i}\left(\theta_{i}, \theta_{M}\right) \geq 0$, and $\sum_{i \in M} \theta_{i}=m \theta_{M}$, where $\theta_{i}$ is firm $i$ 's marginal cost. We consider only two examples below.

\subsection{Semi-collusion in Bertrand Games}

Consider a multidivisional firm that has $m$ independent divisions producing differentiated products. In stage two of the game, the divisions choose their prices simultaneously. Let $p_{i}$ denote division $i$ 's price and $p_{-i}$ denote the vector of prices chosen by its opponents. The demand for division $i$ 's output is $q_{i}=D^{i}\left(p_{i}, p_{-i}\right)$. The total cost of producing $q_{i}$ is $C^{i}\left(q_{i}, k_{i}\right)$, where $k_{i}$ is the capital stock of division $i$. Let $\widehat{p}_{i}$ denote firm $i$ 's price at the Bertrand equilibrium, and $\widehat{q}_{i}$ the corresponding quantity.The following conditions characterize an interior Bertrand equilibrium, which we assume to be unique:

$$
\widehat{p}_{i}=\theta_{i}+\frac{\widehat{q}_{i}}{\left[-D_{i}^{i}\right]}
$$

where $\frac{\partial D^{i}}{\partial p_{i}} \equiv D_{i}^{i}<0$ by assumption, and $\theta_{i} \equiv \frac{\partial C^{i}\left(\widehat{q}_{i}, k_{i}\right)}{\partial q_{i}}>0$ Division $i$ 's equilibrium profit is

$$
\pi_{i}=\widehat{p}_{i} D^{i}-C^{i}=\left[\theta_{i}+\frac{D^{i}}{\left[-D_{i}^{i}\right]}\right] D^{i}-C^{i}=\frac{\widehat{q}_{i}^{2}}{\left[-D_{i}^{i}\right]}+\left(\epsilon_{i}-1\right) C^{i}
$$

where $\epsilon_{i} \equiv q_{i} \theta_{i} / C^{i}$ is the elasticity of the cost function $C^{i}$.

Let the average price be denoted by $p_{M}=(1 / m) \sum_{i \in M} p_{i}$ and assume that the demand functions take the form

\footnotetext{
${ }^{13}$ See Long and Soubeyran (1997b).
} 


$$
q_{i}=d_{i}\left(p_{M}\right)-\delta_{i} p_{i}
$$

where $\delta_{i}>0$, and $0 \leq d_{i}^{\prime}\left(p_{M}\right) \leq \delta_{i}$, so that if all division increase their prices by the same amount, then the quantity demanded falls. Then, from (50) and (52)

$$
\widehat{p}_{i}=\frac{1}{2}\left[\theta_{i}+\frac{1}{\delta_{i}} d_{i}\left(\widehat{p}_{M}\right)\right]
$$

Summing (53) over all $i$, we obtain the analog of Lemma 1 , that is, the average price in a Bertrand equilibrium is uniquely determined by the sum of marginal costs $\Theta=\sum_{i \in M} \theta_{i}$ and is independent of the distribution of marginal costs among the divisions:

$$
\widehat{p}_{M}-\sum_{i \in M} \frac{d_{i}\left(\widehat{p}_{M}\right)}{2 m \delta_{i}}=\frac{\Theta}{2 m}
$$

Thus $\widehat{p}_{M}=\widehat{p}_{M}(\Theta)$ with $\widehat{p}_{M}^{\prime}(\Theta)>0$. Substituting this function into (52), and using (53), we obtain the equilibrium output for each division:

$$
\widehat{q}_{i}\left(\theta_{i}, \Theta\right)=\frac{1}{2}\left[d_{i}\left(\widehat{p}_{M}(\Theta)\right)-\delta_{i} \theta_{i}\right]
$$

Finally, substituting (55) into (51), we obtain the equilibrium profit function

$$
\pi_{i}\left(\theta_{i}, \Theta\right)=\frac{\left[\widehat{q}_{i}\left(\theta_{i}, \Theta\right)\right]^{2}}{\delta_{i}}+\left(\epsilon_{i}-1\right) C^{i}\left(\widehat{q}_{i}\left(\theta_{i}, \Theta\right), \alpha_{i}\right)
$$

In the first stage of the game, the multi-divisional firm allocate capital stocks to the division, so as to maximize overall profit. The two-stage game with Bertrand competition in the second stage is therefore very similar to the two-stage Cournot games analyzed in Section 2.

\subsection{Semi-collusion in the Hotelling model of location}

In thee Hotelling model (see Tirole (1988, pp. 279-281)) with a linear city, it is assumed that two firms compete in prices in the second stage, and make their location choice in the first stage. Consumers are uniformly located in the city, and they incur a quadratic transport cost $t d^{2}$ if $d$ is the distance they must travel to get to good. The two extremes of the linear city are denoted by 0 and 1 . Let $a$ and $b$ be firm 1 's and firm 2 's location respectively, where $0 \leq a \leq b \leq 1$. Tirole (1988, p. 281) shows that the Nash equilibrium choice of location exhibits maximal 
distance between the firms. Our approach can be adapted to study the collusive choice of location in the first stage of the game. To generalize the model a bit further, assume that a firm's unit cost depends on its location, possibly because of proximity to input suppliers etc. It can be shown that given $a$ and $b$, the equilibrium profits in stage one are

$$
\pi_{1}=\frac{1}{18 t(1-a-b)}\left\{t\left[(2-b)^{2}-(1+a)^{2}\right]-2\left[c_{1}(a)-c_{M}(a, b)\right]\right\}^{2}
$$

and

$$
\pi_{2}=\frac{1}{18 t(1-a-b)}\left\{t\left[(2-a)^{2}-(1+b)^{2}\right]-2\left[c_{2}(1-b)-c_{M}(a, b)\right]\right\}^{2}
$$

where $c_{M}$ is the average of $c_{1}(a)$ and $c_{2}(1-b)$.

The sum of the two profit expressions is

$$
\Pi=\frac{1}{18 t(1-a-b)}\left[h t^{2}-4 t \Delta+8 V_{M}\right]
$$

where $V_{M}$ is the variance of the costs, as defined by (10), which in this case depends on $a$ and $b$, and where

$$
h=\left[(2-b)^{2}-(1+a)^{2}\right]^{2}+\left[(2-a)^{2}-(1+b)^{2}\right]^{2}
$$

and

$\Delta=4 t\left(c_{1}-c_{M}\right)\left[(2-b)^{2}-(1+a)^{2}\right]+4 t\left(c_{2}-c_{M}\right)\left[(2-a)^{2}-(1+b)^{2}\right]$

Suppose, for example, that each firm's cost is a decreasing function of its distance from the city center (the point $1 / 2$ ). Then $V_{M}$ will be minimized when $a=b=1 / 2$. Since (57) is increasing in $V_{M}$ there is an incentive for the two firms to agree to be located rather far apart. The precise solution depends on the specification of the functions $c_{1}(a)$ and $c_{2}(1-b)$, and examples can be constructed to show that asymmetric locations are optimal for this semi-collusion problem.

\section{Conclusion}

We have provided a framework for analysis of two-stage games of cost manipulation, where the manipulation involves real resource costs. The basic model of this paper describes one important aspect of "co-opetition" within an oligopoly: how rival firms jointly manipulate their costs of production, by implicit or explicit cooperation, using real resource, in the 
first stage of the game. This form of semi-collusion can place (semi) rival firms in a better position in the second stage, where they are really rivals. We showed that cost manipulations may give rise to symmetric or asymmetric outcomes. We characterized the solution, using a global approach, and show the geometric nature of the solution. We focused on the constant marginal cost case, but the generalization given in Section 3 , for the case of 'rankable convex costs', the first application in Section 4, and the extensions considered in Appendix A2 show that our approach has a wide range of applications.

The various applications discussed in this paper share a common characteristic: firms' marginal costs are manipulated by the allocation and/or production of resources, such as the stock of internally produced assets (human or non-human), or by using other choice variables such as location. There are, in general, non-linear tradeoffs between reduction of production costs in stage two, and resource costs in stage one. Our model offers an explanation of the emergence of an internal market within a multi-divisional firm, or more generally, a group of oligopolists. While we have focused on the theory of oligopoly, it is clear that our framwork is applicable to other situations, for example, investment to manipulate peer pressure and guilt in a social or economic partnership (see Kandel and Lazear (1992) for an interesting discussion.)

A quite different class of cost manipulation, with cost of manipulating, involves the use of taxes and subsidies. It may be thought at first that these are pecuniary transfers and thus have no real costs. Upon reflection, however, there is the cost of public finance, because any subsidy to firms must typically be financed by taxing consumers in a distortionary manner. Also, to the extent that some firms are partly foreign-owned, subsidies are partially 'leaked' away from the home country. The optimal taxation problem in the context of two-stage Cournot oligopoly games is therefore not trivial. An analysis of this class of cost manipulation problem is the subject matter of a companion paper, Long and Soubeyran (1997a). 


\section{Appendices}

\section{A.1: Proof of Corollary 1:}

From (8) and (7), industry profit is

$$
m \pi_{M} \equiv \sum_{i \in M} \pi_{i}\left(c_{i}, C\right)=\sum_{i \in M}\left(-P^{\prime}\right) q_{i}^{2}
$$

and the Herfindahl index is

$$
H_{M} \equiv \sum_{i \in M}\left[\frac{q_{i}}{Q}\right]^{2}=\frac{1}{Q^{2}} \sum_{i \in M} q_{i}^{2}
$$

Therefore

$$
m \pi_{M}=\left(-P^{\prime}\right) Q^{2} H_{M}
$$

This completes the proof. $\square$

A.2: A unifying treatment of the models of "co-opetition".

The second stage of the various games we considered in the main text takes the following generic form: Player $i \in N=\{1, \ldots, n\}$ has the pay-off function $G_{i}\left(x_{i}, n x_{N}, \alpha_{i}\right)$ where $x_{N}=(1 / n) \sum_{i \in N} x_{i}$, where $x_{i} \in X_{i}$ is the action taken by $i$ and $\alpha_{i}$ is a parameter that all the players jointly manipulate in stage one. Let $\boldsymbol{\alpha}=\left(\alpha_{1}, \ldots, \alpha_{n}\right)$. The Nash equilibrium (assumed to be unique) in the second stage gives the equilibrium $\widehat{x}_{i}(\boldsymbol{\alpha}), i \in N$. Let $M$ be a subset of players that collude in stage one, even though they will be rivals in stage two. Without loss of generality, let $M=\{1, \ldots, m\}$. The sum of the stage two equilibrium payoffs of members of $M$ is $\sum_{i \in M} G_{i}\left(x_{i}, n x_{N}, \alpha_{i}\right)=m \widehat{G}_{M}$. (In what follows we set $M=N$ for simplicity, and consider Cournot games, so that we identify the action $x_{i}$ with the output $q_{i}$, and the parameter $\alpha_{i}$ is used to influence the marginal $\operatorname{cost} \theta_{i}$.)

Let firm $i$ 's production cost be $C_{i}\left(q_{i}, \alpha_{i}\right)$ where both partial derivatives are positive. Assume $C_{i}\left(q_{i}, \alpha_{i}\right)$ is strictly convex in $q_{i}$. Let $\widehat{q}_{i}$ be the ournot equilibrium output of firm $i$. Let $\theta_{i}$ denote the marginal cost at the equilibrium:

$$
\theta_{i} \equiv \frac{\partial C_{i}\left(\widehat{q}_{i}, \alpha_{i}\right)}{\partial q_{i}}
$$

Invert this equation to obtain $\alpha_{i}=\alpha_{i}\left(\widehat{q}_{i}, \theta_{i}\right)$. The industry output in the Cournot equilibrium in stage 2 is $\widehat{Q}=Q\left(\theta_{M}\right)$. Then

$$
\widehat{q}_{i}=\frac{\widehat{P}-\theta_{i}}{\left[-\widehat{P}^{\prime}\right]}
$$


Much simplicity is achieved by noting that the manipulation of the $\theta_{i} \mathrm{~s}$ is equivalent to manipulating the parameters $a_{i}$ s, in view of the one-to-one relationships that must hold at a Cournot equilibrium:

$$
\theta_{i}=\frac{\partial C_{i}}{\partial q_{i}}\left(\widehat{q}_{i}, \alpha_{i}\right)=\frac{\partial C_{i}}{\partial q_{i}}\left(\frac{\widehat{P}-\theta_{i}}{\left[-\widehat{P}^{\prime}\right]}, \alpha_{i}\right)
$$

This gives $\alpha_{i}=\alpha_{i}\left(\theta_{i}, \theta_{M}\right)$. Firm $i$ 's cost function can thus be represented as

$$
\widetilde{C}_{i}\left(\theta_{i}, \theta_{M}\right)=C_{i}\left[\frac{\widehat{P}-\theta_{i}}{\left[-\widehat{P}^{\prime}\right]}, \alpha_{i}\left(\theta_{i}, \theta_{M}\right)\right]
$$

and its equilibrium profit function is

$$
\widehat{\pi}_{i}\left(\theta_{i}, \theta_{M}\right)=\frac{\widehat{P}-\theta_{i}}{\left[-\widehat{P}^{\prime}\right]} P\left(\widehat{Q}\left(\theta_{M}\right)\right)-\widetilde{C}_{i}\left(\theta_{i}, \theta_{M}\right)
$$

The industry gross profit (i.e,. before subtracting the costs of manipulating $\left.\operatorname{costs} \phi_{i}\left(\theta_{i}, \theta_{M}\right)\right)$ in the Cournot equilibrium is

$$
m \widehat{\pi}_{M}=\frac{\widehat{P}-\theta_{M}}{\left[-\widehat{P}^{\prime}\right]} P\left(\widehat{Q}\left(\theta_{M}\right)\right)-\sum_{i \in M} \widetilde{C}_{i}\left(\theta_{i}, \theta_{M}\right)
$$

Define

$$
G\left(\theta_{M}\right)=\frac{\widehat{P}-\theta_{M}}{\left[-\widehat{P}^{\prime}\right]} P\left(\widehat{Q}\left(\theta_{M}\right)\right)
$$

From (63) and (64), it is clear that the first stage problem has the following form:

$$
\max _{\theta_{i}} J=-\sum_{i \in M} f_{i}\left(\theta_{i}, \theta_{M}\right)
$$

subject to $\sum_{i \in M} \theta_{i}=m \theta_{M}$. (with $\theta_{i} \geq 0$.) Note that $f_{i}\left(\theta_{i}, \theta_{M}\right)$ stands for $C_{i}\left(\theta_{i}, \theta_{M}\right)-(1 / m) G\left(\theta_{M}\right)+\phi_{i}\left(\theta_{i}, \theta_{M}\right)$. We solve this problem in two steps.

(i) First we fix the mean marginal cost $\theta_{M}$. It is as if we fixed the final price of the good, when $N=M$, which is the case we consider here.) At this step, we solve the simplified problem:

$$
\min S=\sum_{i \in M} f_{i}\left(\theta_{i}, \theta_{M}\right)
$$

subject to $\sum_{i \in M} \theta_{i}=m \theta_{M}$ (with $\theta_{i} \geq 0$, and $\theta_{M}$ is fixed). (It is possible to include another constraint of the form $\sum_{i \in M} g\left(\theta_{i}, \theta_{M}\right) \geq 0$ which 
represents resource constraints on the manipulation of costs; however we shall omit this for simplicity.) This is a well-known separable nonlinear programming problem, called the inf-convolution problem. Its resolution uses duality theory via conjugate functions, see Rockafellar (1970, section 28), Luenberger (1969, Chapter 8). Note that by fixing $\theta_{M}$, the final price of the good is fixed, and so is total industry output. Given this stage two equilibrium, in stage 1 the rivals jointly manipulate their marginal costs $\theta_{i}, i \in M$, to minimize the industry's total cost of producing the given equilibrium output $\widehat{Q}\left(\theta_{M}\right)$ (including the cost of manipulating costs), given that they are rivals in stage two. Let us describe the inf-convolution approach. We face the standard infconvolution problem:

$$
\max _{\theta_{i} \in M}-\sum_{i \in M} f_{i}\left(\theta_{i}, \theta_{M}\right)
$$

subject to $\sum_{i \in M} \theta_{i}=m \theta_{M}, \theta_{i} \geq 0$, for a given $\theta_{M}$. This is where the mathematical duality theory can be applied, with the use of the concept of conjugate functions, as described below. Construct the Lagrangian

$$
L=-\sum_{i \in M} f_{i}\left(\theta_{i}, \theta_{M}\right)+\lambda\left[-m \theta_{M}+\sum_{i \in M} \theta_{i}\right]
$$

Then, making use of the separability property, we obtain

$$
L=\sum_{i \in M}\left[\lambda \theta_{i}-f_{i}\left(\theta_{i}, \theta_{M}\right)\right]-\lambda m \theta_{M}
$$

For an interior solution, the first order conditions $\frac{\partial f_{i}}{\partial \theta_{i}}\left(\theta_{i}, \theta_{M}\right)=\lambda$ give $\theta_{i}=\widetilde{\theta}_{i}\left(\lambda, \theta_{M}\right)$. Following Rockafellar (1970), define the conjugate function $f_{i}^{*}$ of $f_{i}$ as follows

$$
f_{i}^{*}\left(\lambda, \theta_{M}\right)=\sup _{\theta_{i} \geq 0}\left[\lambda \theta_{i}-f_{i}\left(\theta_{i}, \theta_{M}\right)\right]
$$

Then $f_{i}^{*}\left(\lambda, \theta_{M}\right)=\lambda \widetilde{\theta}_{i}\left(\lambda, \theta_{M}\right)-f_{i}\left(\widetilde{\theta}_{i}\left(\lambda, \theta_{M}\right), \theta_{M}\right)$.

Recall that $\lambda$ must satisfy $\sum_{i \in M} \widetilde{\theta}_{i}\left(\lambda, \theta_{M}\right)=m \theta_{M}$, and this equation gives $\lambda=\widetilde{\lambda}\left(\theta_{M}\right)$. (More generally, $\widetilde{\lambda}\left(\theta_{M}\right)$ can be obtained from the saddle-point Lagrangian theorem.)

Next, the optimal $\theta_{M}$ is obtained from solving the problem

$$
\max _{\theta_{M}} \widetilde{L}=-\widetilde{\lambda}\left(\theta_{M}\right) m \theta_{M}+\sum_{i \in M} f_{i}^{*}\left(\widetilde{\lambda}\left(\theta_{M}\right), \theta_{M}\right)
$$


Here, the use of duality, as reflected in the conjugate functions $f_{i}^{*}$, is illuminating. The duality saddle-point theorem allows us to dtermine the optimal $\theta_{M}$ as the solution of $\frac{\partial \widetilde{L}}{\partial \theta_{M}}=0$. From (65), we get

$$
\frac{\partial \widetilde{L}}{\partial \theta_{M}}=-\widetilde{\lambda}\left(\theta_{M}\right) m-m \theta_{M} \frac{\partial \widetilde{\lambda}}{\partial \theta_{M}}+\sum_{i \in M}\left[\frac{\partial f_{i}^{*}}{\partial \widetilde{\lambda}} \frac{\partial \widetilde{\lambda}}{\partial \theta_{M}}+\frac{\partial f_{i}^{*}}{\partial \theta_{M}}\right]
$$

Using the envelope property that $\frac{\partial f_{i}^{*}}{\partial \widetilde{\lambda}}=\widetilde{\theta}_{i}$, we obtain the simplified condition

$$
\frac{\partial \widetilde{L}}{\partial \theta_{M}}=-\widetilde{\lambda}\left(\theta_{M}\right) m+\sum_{i \in M} \frac{\partial f_{i}^{*}}{\partial \theta_{M}}=0
$$

where, again due to the envelope theorem, $\frac{\partial f_{i}^{*}\left(\widetilde{\lambda}, \theta_{M}\right)}{\partial \theta_{M}}=-\frac{\partial f_{i}\left(\theta_{i}, \theta_{M}\right)}{\partial \theta_{M}}$. This equation determines the optimal $\theta_{M}$. 


\section{References}

[1] Bagwell, K. and R. Steiger, 1994, The Sensitivity of Strategic and Corrective R\&D Policy in Oligopolistic Industries, Journal of International Economics, 36, 133-50.

[2] Baye, Michael R., Keith J. Crocker, and Jiandong Ju, 1996, Divisionalization, Franchising, and Divestiture Incentives in Oligopoly, American Economic Review 86, 223-36.

[3] Bergstrom, Theodore and Hal Varian,1985a, When are Nash Equilibria Independent of the Distribution of Agents 'Characteristics?, Review of Economic Studies 52, 715-18.

[4] Bergstrom, Theodore and Hal Varian, 1985b, Two Remarks on Cournot Equilibria, Economics Letters 19, 5-8.

[5] Bergstrom, Theodore, Lawrence Bloom, and Hal Varian, 1986, On the Private Provision of Public Goods, Journal of Public Economics $29,25-49$.

[6] Besley, T. and K. Suzumura,1992, Taxation and Welfare in an Oligopoly with Strategic Commitment, International Economic Review, 33, 413-31

[7] Binmore, Ken, Ariel Rubinstein, and A. Wolinsky, 1986, The Nash Bargaining Solution in Economic Modelling, Rand Journal of Economics $17,176-88$.

[8] Brander, James and Barbara Spencer, 1983, Strategic Commitment with R\&D: the Symmetric Case, Bell Journal of Economics, 14, $225-35$.

[9] D'Aspremont, Claude and Alexis Jacquemin, 1988, Cooperative R\&D in Duopoly with Spillovers, American Economic Review, 78, 1133-37.

[10] Daughety, Andrew (1990), Beneficial Concentration, American Economic Review 80, 5, 1231-37.

[11] DeGraba, P., 1990, Input Market Price Discrimination and the Choice of Technology, American Economic Review 80, 1246-53.

[12] Dixit, Avinash, 1986, Comparative Statics for Oligopoly, International Economic Review 27, 107-22. 
[13] Farrell, Joseph, and Carl Shapiro,1990a, Asset Ownership and Market Structure in Oligopoly, Rand Journal of Economics 21, 2, 27592.

[14] Farrell, Joseph, and Carl Shapiro, 1990b, Horizontal Mergers: an Equilibrium Analysis, American Economic Review 80, 1, 107-26.

[15] Fershtman, Chaim, and Neil Gandal, 1994, Disadvantageous Semicollusion, International Journal of Industrial Organization: 12, pp 141-154.

[16] Foss, Nicolai J., Christian Knudsen, and Cynthia A. Montgomery, 1995, An Exploration of Common Ground: Integrating Evolutionary and Strategic Theory of the Firm, in Cynthia A. Montgomery (ed.), Resource-Based and Evolutionary Theories of the Firm: Towards a Synthesis, Kluwer, Boston.

[17] Friedman, James W., and Jacques-François Thisse, 1993, Partial Collusion Fosters Minimum Product Differentiation, RAND Journal of Economics 24, pp. 631-645.

[18] Fudenberg, Drew, and Jean Tirole, 1983, Learning-by-Doing and Market Performance, Bell Journal of Economics, 14, 522-30.

[19] Gaudet, Gerard, and Stephen Salant 1991, Uniqueness of Cournot Equilibrium: New Results from Old Methods, Review of Economic Studies 58, 399-404.

[20] Gale, Ian, 1994, Price Competition in Non-cooperative Joint Ventures, International Journal of Industrial Organization 12, pp. 5369.

[21] Grafton, Quentin, and Rose Anne Devlin, 1996, Paying for Pollution: Permits and Charges, Scandinavian Journal of Economics 98, $2,275-88$.

[22] Kamien, Morton, Eitan Muller, and Israel Zang, 1992, Research Joint Ventures and R\&D Cartels, American Economic Review 82, 5, 1293-1306.

[23] Kandel, Eugene, and Edward Lazear, 1992, Peer Pressure and Partnership, Journal of Political Economy 100, pp. 801-817.

[24] Kolstad Charles, and Lars Mathieson, 1987, Necessary and Sufficient Conditions for Uniqueness of a Cournot Equilibrium, Review of Economic Studies 54, 681-90. 
[25] Krouse, Clement G., 1994, Market Rivalry and Learning-by-Doing, International Journal of Industrial Organization, 12, 437-456.

[26] Long, Ngo Van, and Antoine Soubeyran, 1995a, Greater Cost Dispersion Improves Oligopoly Profits: Asymmetric Contributions to Joint Ventures, GREQAM Working Paper 95A10, in J. A. PoyagoTheotoky (Ed.), Competition, Cooperation, and RGD: the Economics of Research Joint Ventures, Macmillan, London, 1977, 12637.

[27] Long, Ngo Van, and Antoine Soubeyran, 1995b, Asymmetric Contributions to Research Joint Ventures, GREQAM Working Paper 95-A 15

[28] Long, Ngo Van, and Antoine Soubeyran, 1997a, Cost Heterogeneity, Industry Concentration, and Strategic Trade Policies, Journal of International Economics, 43, pp. 207-220.

[29] Long, Ngo Van, and Antoine Soubeyran,1997a, Cost Manipulation in a Cournot Oligopoly: The Taxation Problem, SEEDS Discussion Paper 173, Southern European Economics Discussions Series.

[30] Long, Ngo Van, and Antoine Soubeyran,1997b, Cost Manipulation in a Cournot Oligopoly: a Duality Approach, SEEDS Discussion Paper 174, Southern European Economics Discussions Series.

[31] Long, Ngo Van, and Antoine Soubeyran,1999, Existence and Uniqueness of Cournot Equilibrium: A New Approach, Typescript, CIRANO, Montréal

[32] Luenberger, D., !969, Optimization by Vector Space Methods, Wiley, New York.

[33] Newbery, David 1990, Acid Rain, Economic Policy 11, 298-346.

[34] Nalebuff, B. J. and A. M. Brandenburger, 1996, Co-opetition, Doubleday, Bantam Doubleday Dell Publishing Group.

[35] Nishimura, Kazuo, and James Friedman, 1881, Existence of Nash Equilibrium in $\mathrm{n}$ Person Games without Quasi-concavity, International Economic Review 22, 3, 637-48.

[36] Rockafellar, R. Tyrell, 1970, Convex Analysis, Princeton University Press, Princeton, N.J. 
[37] Salant, Stephen and Greg Shaffer, 1992, Optimal Asymmetric Strategies in Research Joint Ventures: A Comment on the Literature, Typescript, University of Michigan.

[38] Salant, Stephen and Greg Shaffer, 1996, Unequal Treatment of Identical Agents in Cournot Equilibrium: Private and Social Advantages, Typescript, University of Michigan.

[39] Salant, Stephen, Sheldon Switzer, and Robert J. Reynolds, 1983, Losses From Horizontal Merger: The Effects of an Exogenous Change in Industry Structure on Cournot-Nash Equilibrium, Quarterly Journal of Economics 98, pp 185-199.

[40] Schwartz, Marius and Earl A. Thompson, 1986, Divisionalization and Entry Deterrence, Quarterly Journal of Economics 101, 30721.,

[41] Spencer, B. J., and R. S. Raubitschek, 1996, High-cost Domestic Joint Ventures and International Competition: Do Domestic Firms Gain?, International Economic Review 37, 315-340.

[42] Suzumura, Kotaro, 1992, Cooperative and non-cooperative R\&D in an Oligopoly with Spillovers, American Econmic Review 82, 5, 1307-20.

[43] Tirole, Jean, 1988, The Theory of Industrial Organization, MIT Press.

[44] Veendorf, E. C. H. ,1991, Entry Deterrence, Divisionalization, and Investment Decisions, Quarterly Journal of Economics 106, pp. 297307.

[45] Williamson, Oliver E., 1975, Markets and Hierarchies: Analysis and Antitrust Implications, New York, Free Press.

[46] World Investment Report (1993), Transnational Corporations and Integrated International Production, United Nations Conference on Trade and Development. 


\section{Liste des publications au CIRANO *}

\section{Cahiers CIRANO / CIRANO Papers (ISSN 1198-8169)}

96c-1 Peut-on créer des emplois en réglementant le temps de travail ? / Robert Lacroix

95c-2 Anomalies de marché et sélection des titres au Canada / Richard Guay, Jean-François L'Her et Jean-Marc Suret

95c-1 La réglementation incitative / Marcel Boyer

94c-3 L'importance relative des gouvernements : causes, conséquences et organisations alternative / Claude Montmarquette

94c-2 Commercial Bankruptcy and Financial Reorganization in Canada / Jocelyn Martel

94c-1 Faire ou faire faire : La perspective de l'économie des organisations / Michel Patry

\section{Série Scientifique / Scientific Series (ISSN 1198-8177)}

99s-12 Using Employee Level Data in a Firm Level Econometric Study / Jacques Mairesse et Nathalie Greenan

99s-11 Incentives for Poluution Control: Regulation or (and?) Information / Jérôme Foulon, Paul Lanoie et Benoît Laplante

99s-10 Le coût du capital des entreprises à base de connaissance au Canada / Jean-Marc Suret, Cécile Carpentier et Jean-François L'Her

99s-09 Stratégies de financement des entreprises françaises : Une analyse empirique / Cécile Carpentier et Jean-Marc Suret

99s-08 Non-Traded Asset Valuation with Portfolio Constraints: A Binomial Approach / Jérôme Detemple et Suresh Sundaresan

99s-07 A Theory of Abuse of Authority in Hierarchies / Kouroche Vafaï

99s-06 Specific Investment, Absence of Commitment and Observability / Patrick González

99s-05 Seasonal Nonstationarity and Near-Nonstationarity / Eric Ghysels, Denise R. Osborn et Paulo M. M. Rodrigues

99s-04 Emerging Markets and Trading Costs / Eric Ghysels et Mouna Cherkaoui

99s-03 Sector-Specific Training and Mobility in Germany / Lars Vilhuber

99s-02 Women's Wages in Women's Work: A US/Canada Comparison of the Roles of Unions and 'Public Goods' Sector Jobs / Michael Baker et Nicole M. Fortin

99s-01 Globalization and Worker Welfare in Late Nineteenth Century Europe / Michael Huberman et Wayne Lewchuk

98s-41 Dynamic Equilibrium with Liquidity Constraints / Jérôme Detemple et Angel Serrat

98s-40 Monetary Policy Rules with Model and Data Uncertainty / Eric Ghysels, Norman R. Swanson et Myles Callan

98s-39 Environmental Risks: Should Banks Be Liable? / Karine Gobert et Michel Poitevin

98s-38 Better Observability Promotes the Adoption of More Flexible Technologies / Marcel Boyer, Armel Jacques et Michel Moreaux

* Vous pouvez consulter la liste complète des publications du CIRANO et les publications elles-mêmes sur notre site World Wide Web à l'adresse suivante :

http://www.cirano.umontreal.ca/publication/page1.html 